2017-04

\title{
On the hindered settling of sand-mud suspensions
}

Spearman, J

http://hdl.handle.net/10026.1/9464

10.1007/s10236-017-1034-7

Ocean Dynamics

Springer Science and Business Media LLC

All content in PEARL is protected by copyright law. Author manuscripts are made available in accordance with publisher policies. Please cite only the published version using the details provided on the item record or document. In the absence of an open licence (e.g. Creative Commons), permissions for further reuse of content should be sought from the publisher or author. 


\section{On the hindered settling of sand-mud suspensions}

\section{Jeremy Spearman \& Andrew J. Manning}

\section{Ocean Dynamics}

Theoretical, Computational and Observational Oceanography

ISSN 1616-7341

Ocean Dynamics

DOI 10.1007/s10236-017-1034-7

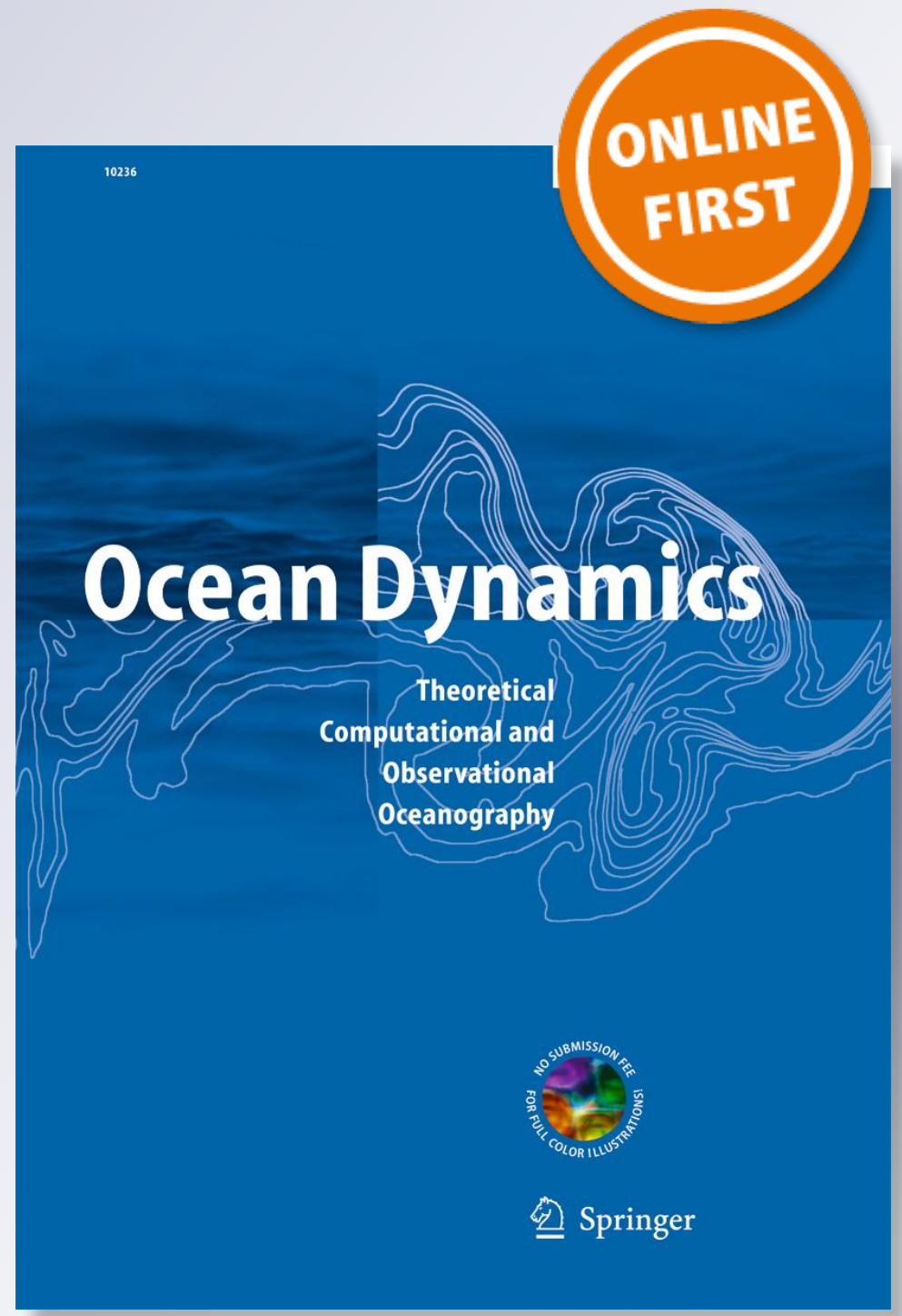

算 Springer 
Your article is protected by copyright and all rights are held exclusively by SpringerVerlag Berlin Heidelberg. This e-offprint is for personal use only and shall not be selfarchived in electronic repositories. If you wish to self-archive your article, please use the accepted manuscript version for posting on your own website. You may further deposit the accepted manuscript version in any repository, provided it is only made publicly available 12 months after official publication or later and provided acknowledgement is given to the original source of publication and a link is inserted to the published article on Springer's website. The link must be accompanied by the following text: "The final publication is available at link.springer.com". 


\title{
On the hindered settling of sand-mud suspensions
}

\author{
Jeremy Spearman ${ }^{1}$ • Andrew J. Manning ${ }^{1,2,3}$
}

Received: 13 March 2016 / Accepted: 22 January 2017

(C) Springer-Verlag Berlin Heidelberg 2017

\begin{abstract}
Hindered settling, the process by which the settling of sediment particles becomes impeded due to the proximity of other sediment particles, can be an important process for the coastal modeller, especially in highly muddy environments. It is also a significant process in other disciplines such as chemical engineering, the modelling of debris flow, the study of turbidites, piping of slurries and the understanding of processes occurring within a dredger hopper. This study first examines the hindered settling behaviour of monodisperse suspensions in order to create a framework for polydisperse hindered settling that works for both non-cohesive and cohesive suspensions. The Richardson-Zaki equation is adapted to make it compatible with the changes with viscosity that occur near the point at which suspensions become solid. The modified monodisperse settling equation is then compared to data for hindered settling of cohesive suspensions and shown to be consistent with the transition between hindered settling and the initial permeability phase of consolidation. Based on the monodisperse framework developed initially, this paper proposes a hindered settling model for sand/mud mixtures which
\end{abstract}

This article is part of the Topical Collection on the 13th International Conference on Cohesive Sediment Transport in Leuven, Belgium 7-11 September 2015

Responsible Editor: Erik A Toorman

Jeremy Spearman

j.spearman@hrwallingford.com

1 HR Wallingford, Howbery Park, Wallingford, Oxfordshire OX10 8BA, UK

2 University of Plymouth, Plymouth, Devon PL4 8AA, UK

3 Department of Geography, Environment and Earth Sciences, University of Hull, Hull HU6 7RX, UK is based on a modification of the Masliyah (1979) and Lockett and Bassoon (1979) hindered settling equation. The model is shown to reproduce the hindered settling of a variety of different sediment mixtures whilst reducing the extent of empiricism often associated with the modelling of polydisperse hindered settling of mud/sand mixtures.

Keywords Hindered settling $\cdot$ Mixed sediment $\cdot$ Numerical model $\cdot$ Richardson and Zaki $\cdot$ Permeability $\cdot$ Cohesive sediment

\section{Introduction}

A knowledge of particle settling velocity dynamics is extremely important when considering depositional rates and transport fates of both mixed and non-mixed suspended sediments (e.g. Chesher and Ockenden 1997; van Ledden 2002; Winterwerp et al. 2006; Baugh and Manning 2007; Waeles et al. 2008; Soulsby et al. 2013). Hindered settling - the process by which the settling of sediment particles becomes impeded due to the proximity of other sediment particles - can be an important process for the coastal modeller, especially in highly muddy environments. It is also a significant process in other disciplines such as chemical engineering, the modelling of debris flow, the study of turbidites, piping of slurries and the understanding of processes occurring within a dredger hopper.

The prime texts for coastal modellers regarding hindered settling (e.g. Richardson and Zaki 1954; Soulsby 1997; Winterwerp 1999; van Rijn 2007) were written on the basis of work on monodisperse solutions. These formulae are not directly applicable to the more widely encountered polydisperse solutions containing a range of sand as well as silt and clay fractions. This is because the different fractions interact with each other resulting in departure from the monodisperse 
predictions. It is noted that the discipline of coastal sediment science is by no means the hub of research into hindered settling processes. Much of the research originates from chemical engineering researchers, and indeed, the Richardson and Zaki (1954) paper itself came from this discipline. In addition, major contributions have come from theoretical fluid mechanics, and the important work on polydisperse settling of spheres by Batchelor (1982) is the most prominent example of this. Authors from these various disciplines (e.g. Masliyah 1979; Davis and Gecol 1994; Wang et al. 1995; Winterwerp and Van Kesteren 2004; Cuthbertson et al. 2008; Dorrell et al. 2011) have since adapted these well-known equations, to make them more attributable to bidisperse or polydisperse settling. The applications to polydisperse non-cohesive sediments have been relatively successful (e.g. Davis and Gecol 1994; Dorrell et al. 2011). However, the results for mixed cohesive and noncohesive sediments have to date been unsatisfactory.

Amongst the uncertainties encountered by the researchers of hindered settling is the increase in viscosity with increasing cohesive and non-cohesive sediment concentration. Some of the hindered settling approaches listed above are based on the assumption that the viscosity of the suspension fluid varies with solid concentration in similar fashion to a dilute suspension of spheres. For concentrated or cohesive (floc) suspensions, this is not the case and the effect of solid concentration on viscosity is stronger. Further, many of the hindered settling functions discussed above do not take the effective volume concentration of sediment into account but only consider the strict volumetric concentration. This contrasts with the standard formula for the effect of sediment concentration on viscosity which take sediment packing into account (e.g. Krieger and Dougherty 1959; Chong et al. 1971; Quemada 1977).

A further obstacle has been a lack of suitable experimental data. Whilst there are many settling column studies in the literature reporting the settling of bidisperse or even tridisperse non-cohesive sediments, experiments involving the settling of mixed cohesive and non-cohesive sediments are more limiting. The experiments undertaken by Amy et al. (2006) are notable since they include the settling of both non-cohesive and mixed polydisperse suspensions. In addition, measurements by Te Slaa et al. (2013) and Van and Pham Van Bang (2013) have more recently become available and are used in this study to validate the proposed hindered settling approach.

This paper establishes a common framework for hindered settling for non-cohesive and cohesive sediment based on a modified Richardson-Zaki formula. The paper then discusses the status of the current state of hindered settling knowledge of mixed sediments and suggests a modelling approach based on the Masliyah (1979) and Lockett-Bassoon (1979) polydisperse form of the (modified) Richardson-Zaki formula (henceforth referred to as the MLB model) as a basis for reproducing laboratory observations of polydisperse settling from literature.

\section{Theoretical development}

\subsection{Introduction to the settling of sediment particles}

\subsubsection{Non-cohesive particles}

For $R e_{p}=\frac{d w_{s, 0}}{\nu}<$ about 1 (round sediment particles of about $120-140 \mu \mathrm{m}$ in diameter and density $2650 \mathrm{~kg} / \mathrm{m}^{3}$ settling in water), the flow induced by the falling particle is laminar, the strength of viscous forces at the surface of the particle dominates providing the vast majority of the retarding force, and the terminal settling velocity is given by Stokes law (e.g. Smith and Friedrichs 2011):

$w_{s, 0}=\frac{\left(\rho_{s}-\rho_{w}\right) g d^{2}}{18 \mu}=\frac{\nu D_{*}^{3}}{18 d}$

where $w_{s, 0}$ is the settling velocity of a single grain without the influence of hindered settling, $\rho$ is density (the subscripts $s$ and $w$ indicate sediment particle and fluid, respectively), $g$ is the acceleration due to gravity, $d$ is the diameter of the sediment particle and $\mu$ and $\nu$ are the dynamic and kinematic viscosities of the fluid, respectively; $D *=\left[\frac{g(s-1)}{\nu^{2}}\right]^{1 / 3} d$ and $s=\rho_{S} / \rho_{w}$.

For $R e_{p}>$ around 100 (round sediment particles of around $600-700 \mu \mathrm{m}$ in diameter and density $2650 \mathrm{~kg} / \mathrm{m}^{3}$ settling in water), the flow induced by the falling particle is fully turbulent, and the terminal settling velocity is given by

$F_{D}=\frac{1}{2} \rho_{w} w_{s, 0}^{2} C_{D} A$

where $F_{D}$ is the drag force, $w_{s, 0}$ is the terminal particle velocity of a single particle in still water, $A$ is the crosssectional area of the sediment particle and $C_{D}$ is the (dimensionless) drag coefficient which depends on the shape of the object and on the Reynolds number. In this regime, often referred to as the inertial regime, the settling velocity (for spherical grains) is given by (Leng et al. 2009)

$w_{s, 0}=1.73[(s-1) d g]^{\frac{1}{2}}$

A number of researchers have developed formulae which predict (non-cohesive) settling velocity for the whole range of the viscous drag, intermediate and inertial regimes. Two examples are the formula of Soulsby (1997),

$$
\begin{aligned}
w_{s, 0} & =\frac{\nu}{d}\left[\left(10.36^{2}+1.049 D_{*}^{3}\right)-10.36\right] \text { where } D_{*} \\
& =\left[\frac{g\left(s^{-1}\right)}{\nu^{2}}\right] d \text { and } s=\rho_{S} / \rho_{w}
\end{aligned}
$$


and the modification of Stokes law using the Schiller and Naumann (1933) drag correction (Coulson and Richardson 1955)

$w_{s, 0}=\frac{\left(\rho_{s}-\rho_{w}\right) g d^{2}}{18 \mu} \frac{1}{1+0.15 R e_{p}^{0.687}}$

In practice, these equations predict very similar settling velocities (Smith and Freidrichs 2011).

Whilst Eqs. 1 and 3 are derived on the basis of spherical particles, Soulsby's equation is derived from observations of the settling velocity of natural sands. The angular surfaces and differences in shape between natural sand grains can cause departures from the relations for spherical particles (Wu and Wang 2006). Within this paper, Eq. 4 will be used to determine the settling velocity of sediment grains. The topic of the effect of particle shape is, however, outside the scope of this paper.

At low sediment concentrations, of a few percent (Amy et al. 2006), individual particles settle separately. The distance between particles is such that they do not interact. The settling velocity of individual particles increases with their size and particle density (e.g. Soulsby 1997; Van Rijn 1993), and therefore, in mixed or polydisperse suspensions, the largest and heaviest particles settle quickest and will settle onto the bed first. As sediment concentrations increase, the movement of grains downwards causes an equal volume of interstitial fluid to be displaced upwards. The return currents induced can be strong enough to carry smaller or lighter grains upwards. At high concentrations, segregation of grains is increasingly suppressed. This has attributed to different processes by different authors, e.g. particle interlocking (Davies 1968; Davies and Kaye 1971), hydrodynamic processes (Lockett and AlHabbooby 1974) and high rates of bed aggradation (Amy et al. 2006). Amy et al. (2006) found that this suppression begins to occur for volume concentrations of $\phi \approx 0.2$ and is completely suppressed for concentrations of $\phi \approx 0.6$.

\subsubsection{Cohesive particles}

Cohesive particles such as clays possess strong, molecularscale, electrostatic forces that modify their settling behaviour (van Olphen 1977). In natural environments, cohesiveness is enhanced by biogenic long-chain polymer molecules. These are typically sticky mucopolysaccharides, known as extracellular polymeric substances (EPS; Tolhurst et al. 2002), and can be secreted from epipelic diatoms as they move within the sedimentary layers (Paterson and Hagerthey 2001) and subsequently adhere to individual particle surfaces (Manning et al. 2011a,b). This biological cohesion is considered to dominate its electrostatic counterpart (e.g. Kranck 1984; Gratiot and Manning 2007). Cohesive individual particles in suspension are attracted to one another to form flocculi, which themselves can join together to form microflocs which join to form macroflocs; this is the basis of Krone's (1963) classic hierarchical order of aggregation theory. Biogenic cohesion allows silt and even fine sand particles to form flocs with these cohesive flocs (Manning et al. 2010, Manning et al. 2011a,b; Spearman et al. 2011). For example, epipsammic diatoms can attach to sand grains using their mucilage stalks (Harper and Harper 1967), and Little (2000) found that sticky EPS can efficiently bind to fine sand grains.

The settling velocity of flocs does not follow Stokes law because the structure of flocs is different to that of solid grains. The settling velocity of flocs is a function of their size $D_{\text {floc }}$ and their excess density relative to water. Winterwerp (1999) derived a formula for the settling velocity of single mud flocs in still water (based on the Stokes formula with the Schiller and Naumann correction, but accounting for the changes in floc density with floc size),

$w_{s, 0}=\frac{\alpha}{18 \beta} \frac{\left(\rho_{s}-\rho_{w}\right) g}{\mu} d_{p}^{3-D_{f}} \frac{d_{f}^{D_{f}-1}}{1+0.15 \operatorname{Re}_{p}^{0.687}}$

where $\alpha$ and $\beta$ are shape factors of the flocs, $d_{p}$ is the diameter of primary mud particles, $d_{f}$ is the diameter of the floc, $D_{f}$ is the fractal dimension of the mud floc and $R e_{p}$ is the particle Reynolds number (which itself is a function of $w_{s, 0}$ ). Typically, many of these values are not known. To overcome this problem, some researchers have derived physically based, but empirical, formulations of settling velocity based from the field. One of the most sophisticated of these (Soulsby et al. 2013) is based evaluation of the settling velocity of macroflocs (specified as flocs larger than $160 \mu \mathrm{m}$ in diameter) and microflocs (less than $160 \mu \mathrm{m}$ in diameter) separately,

$w_{S M}=0.095\left(\frac{u_{*}^{3} \xi \bar{d}_{m}^{4}}{\nu^{3} z}\right)^{0.166} g c^{0.22044}\left(\frac{\nu z}{u_{*}^{3} \xi}\right)^{1 / 2} \exp \left[-\left(\frac{u_{* S M}}{u_{*} \xi^{1 / 2}}\right)^{0.463}\right]$

$w_{s \mu}=0.5372\left(\frac{u_{*}^{3} \xi d_{\mu}^{4}}{\nu^{3} z}\right)^{0.39} g\left(\frac{\nu z}{u_{*}^{3} \xi}\right)^{1 / 2} \exp \left[-\left(\frac{u_{* \mu}}{u_{*} \xi^{1 / 2}}\right)^{0.66}\right]$

$$
\begin{aligned}
& r=0.1 \quad X<0 \text { where } X \text { is given by } X=\log 10\left(\phi_{m}\right)+6 \\
& r=0.1+0.221 X \quad 0 \leq X<4.07 \\
& \begin{array}{lll}
r=1 & X \quad &
\end{array} \\
& w_{s, a v, 0}=\max \left[r \cdot w_{s M}+(1-r) \cdot w_{s \mu}\right]
\end{aligned}
$$

In these equations, $w_{s M}$ and $w_{s \mu}$ are the average settling velocities of the macrofloc and microfloc populations, 
respectively, $u_{*}$ is the friction velocity, $\xi=1-z / h$ where $h$ is the water depth, $\nu$ is the viscosity of water, $g$ is the acceleration due to gravity, $\bar{d}_{m}$ and $d_{\mu}$ are representative length scales and $u_{* s M}$ and $u_{* s \mu}$ are empirical coefficients. These equations have been derived from data from several NW European estuaries and therefore are representative of natural estuarine conditions in this geographic location, but they are not likely to be representative of the laboratory tests described later in this paper.

As turbidity levels rise above a few $\mathrm{kg} / \mathrm{m}^{3}$, cohesive particles experience hindered settling effects for concentrations (e.g. Maude and Whitmore 1958; Ross 1988; Mehta et al. 2009; Manning et al. 2012). The hindered settling process is important for creating highly concentrated benthic suspensions (sometimes referred to as fluid mud) which can rheologically behave in a non-Newtonian manner, with a viscosity varying up to several hundred times larger than that of clear water (Faas 1984; Wallingford 1990). Their flow is usually laminar and is often characterised by flow downslope under the force of gravity.

Suspensions can display different settling behaviours depending on the initial condition. For volume concentrations above a value, $\phi_{\text {crit }}$ (see Fig. 1), analysis of settling behaviour in settling columns shows that only one interface (between clear water and the settled bed) will be created. Above this value, two interfaces are created - one between overlying clearer water and the settling suspension and the second between the suspension and the bed (Dankers 2006).

When the average distance between flocs becomes sufficiently small, they join together to form a volume-filling network. This point, known as the gel point (with a volume concentration of $\left.\phi_{g e l}\right)$, marks the transition between hindered settling and the permeability phase of consolidation, where the settling velocity function is mainly driven by the compression of flocs and expulsion of pore water (where effective stresses are zero) as shown in Fig. 1. This gelling process can result in measurable strength building up which resists re-entrainment, although this is a thixotropic process (Toorman 1997). The gel

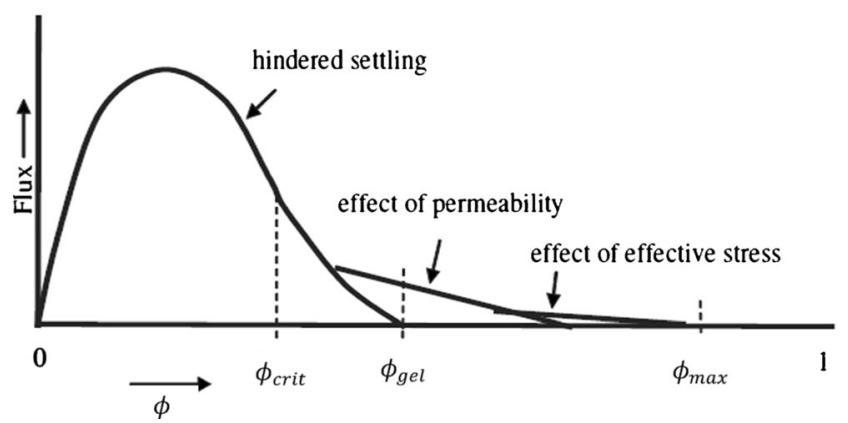

Fig. 1 Schematic figure of the variation of the settling flux with the concentration volume, $\phi_{p}$, showing the hindered settling, and permeability-dominated and effective stress-dominated phases of consolidation. Figure reproduced from Dankers (2006) with parameters renamed for the present paper. The meanings of $\phi, \phi_{c r i t}, \phi_{g e l}$ and $\phi_{\max }$ are explained in the text concentration is a function of the mineralogy, water chemistry and organic content but typically occurs at clay concentrations between 30 and $180 \mathrm{~kg} / \mathrm{m}^{3}$ (Whitehouse et al. 2000; Merckelbach and Kranenburg 2004; Camenen and Pham Van Bang 2011).

Following the permeability phase of consolidation, there is a phase of consolidation where the build-up of effective stress within the consolidating soil becomes the dominant process (Fig. 1). Over time, further consolidation occurs, and the volume concentration will tend to a maximum value, $\phi_{\max }$.

\subsection{The hindered settling of non-cohesive monodisperse suspensions}

\subsubsection{Approaches for non-cohesive hindered settling in the literature}

The Richardson and Zaki equation for the settling of spherical spheres (1954) was given as

$w_{s}=w_{s, 0}(1-\phi)^{n}$

where $n$ is a function of the particle Reynolds number and is given by

$$
\begin{array}{ll}
n=(4.65+19.5 d / D) & \text { for } \operatorname{Re}_{p}<0.2 \\
n=(4.35+17.5 d / D) R e_{p}{ }^{-0.03} & \text { for } 0.2<R e_{p}<1.0 \\
n=(4.45+18 d / D) \operatorname{Re}_{p}^{-0.1} & \text { for } 1.0<R e_{p}<200 \\
n=4.45 \operatorname{Re}_{p}^{-0.1} & \text { for } 200<\operatorname{Re}_{p}<500 \\
n=2.39 & \text { for } \operatorname{Re}_{p}>500
\end{array}
$$

where $d$ is the particle diameter, $D$ is the diameter of the container vessel, $R e_{p}$ is the Reynolds particle number, $w_{s, 0}$ is the terminal particle velocity of a single particle in an still water and $\nu$ is the kinematic fluid viscosity. This formula represents the starting point for this paper.

Rowe (1987) derived the convenient approximation for $n$ given by,

$n=\frac{4.7+0.41 R^{0.75}}{1+0.175 R^{0.75}}$

though it is noted that a number of similar, but slightly different, formulae exist. Several are presented in Siwiec (2007). Of note is the formula by Garside and Al-Dibouni (1977), which was found to be more accurate than the Richardson-Zaki formula for the settling of bidisperse and tridisperse spherical particle suspensions (Al-Naafa and Selim 1989),

$\frac{5.1-n}{n-2.7}=0.1 \operatorname{Re}_{p} 0.9$ or $n=\frac{5.1+0.27 R e_{p}^{0.9}}{1+0.1 \operatorname{Re}_{p}^{0.9}}$ 
The variation in the exponent $n$ in the Richardson and Zaki equation (and other similar equations) accounts for the change in the influence of sediment concentration on particle drag as the Reynolds particle number increases, i.e. it accounts for the transition between hindered settling in the Stokes and inertial regimes.

\subsubsection{Deconstruction of the Richardson-Zaki equation and re-consideration of the effect of viscosity}

Winterwerp (1999) argued that hindered settling can be broken down into terms involving viscosity (the form of this term is discussed further below), return currents (scaling as $1-\phi$ ) and buoyancy (scaling as $1-\phi$ ). The viscosity term (which has varying importance depending on the Reynolds particle number) reflects the drag exerted on settling particles in a viscous fluid. The return current term represents the reduction in settling velocity caused by the upward directed flow resulting from continuity effects of those same particles settling through the fluid. The buoyancy term reflects the change in fluid density (and hence the difference in the densities of fluid and particle) caused by the presence of the sediment. Breaking the Richardson-Zaki equation into these three terms gives the following deconstruction:

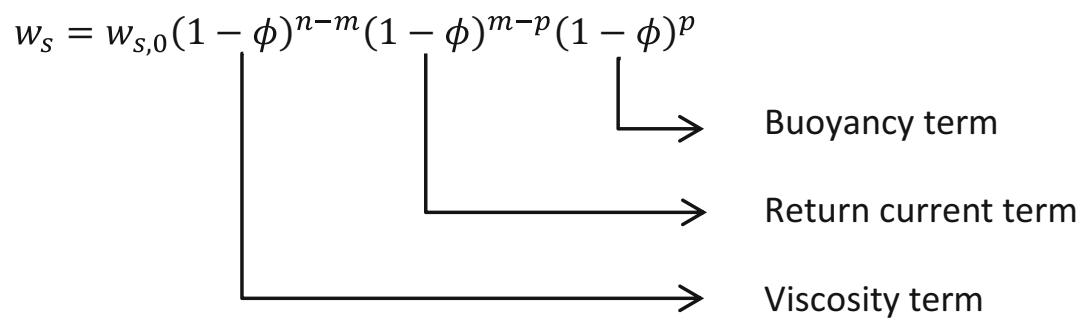

In this deconstruction, $n$ is the Richardson-Zaki exponent, whilst the exponent $m$ accounts for the contribution to hindering of the non-viscosity terms. Using the Rowe approximation of the Richardson and Zaki (1954) formulation, $m$ varies between 1 in the Stokes regime to 2.35 in the inertial regime. $m$ is therefore given by,

$m=2.35-0.35 \frac{n-2.35}{4.7-2.35}=2.5-0.15 n$

The exponent $p$ accounts for the contribution to hindering of the buoyancy terms, and we assume that $p=1$ (Winterwerp and Van Kesteren 2004).

The value $n-m$ accounts for the viscosity terms, but the form of these terms in Eq. 15, $(1-\phi)^{n-m}$, differs from the characterisation of the viscosity of suspensions in the literature. The viscosity of sediment suspensions varies as $\left(1-\phi / \phi_{\max }\right)^{-2}$ (Quemada 1977) or $\left(1-\phi / \phi_{\max }\right)^{-2.5 \cdot \phi_{\max }}$ (Krieger and Dougherty 1959). Therefore, the $(1-\phi)^{n-m}$ term in Eq. 15 needs to be equivalent to $\left(1-\phi / \phi_{\max }\right)^{n^{\prime}}$ where $n^{\prime}$ is an empirical constant related to $n$ and $m$. The $(1-\phi)^{n-m}$ term of Eq. 15 is of a different form to that of the Quesada or Krieger-Dougherty equations since $1-\phi / \phi_{\max }$ approaches zero as the sediment concentration approaches $\phi_{\max }$ (when the sediment suspension becomes a solid) whereas $1-\phi$ does not. Their equivalence can be reconciled, however, if the viscosity term from Eq. 15 represents the viscosity for $\phi \ll \phi_{\max }$ This is indeed true since the value of the exponent $n$ of the Richardson-Zaki equation was derived for values of $\phi$ significantly less than.$\phi_{\max }$ It can be seen from Richardson and Zaki (1954) that as $\phi$ approaches $\phi_{\max }$, the variation of settling speed with porosity $\varepsilon=1-\phi$ increases dramatically. An example from Richardson and Zaki (1954) of this change in behaviour is shown in Fig. 2.

For $\phi \ll \phi_{\max }(1-\phi)^{n-m} \approx\left(1-\phi / \phi_{\max }\right)^{(n-m) \phi_{\max }}=\left(1-\phi / \phi_{\max }\right)^{n^{\prime}}$ It can be seen that for $n=4.5$ (and $m=2$ ), the right-hand term is equal to the reciprocal of the Krieger-Dougherty viscosity, whilst for $\phi_{\max } \approx 0.6$ (which is a typical value for sand grains) and $n=5$ (and $m=2$ ), the right-hand term is equal to the reciprocal of the Quesada viscosity. These limits correspond

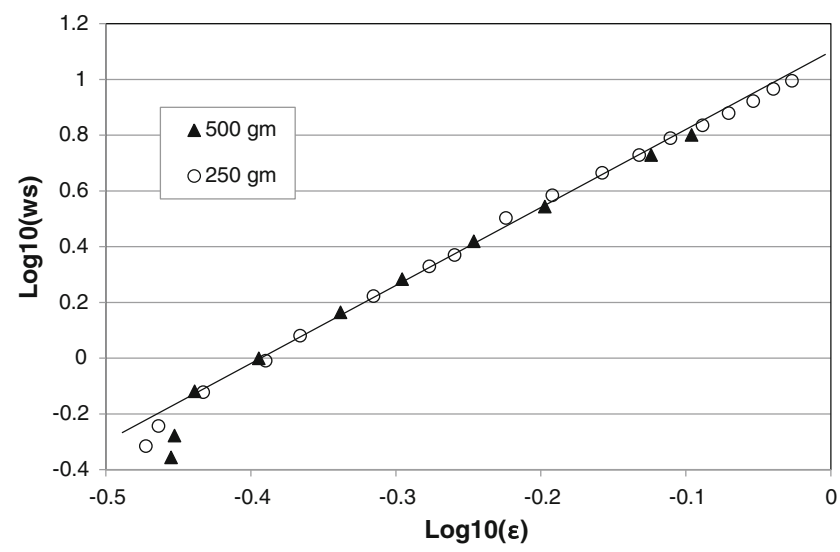

Fig. 2 Example of one of Richardson and Zaki's (1954) experiments (fluidisation of glass ballotini particles of diameter $1.03 \mathrm{~mm}$ ) showing the change in behaviour of the hindered settling behaviour with changes in porosity $\varepsilon$. The units of $w_{s}$ used in the figure are centimetre per second as in the figure from the original paper. The two different groups of data points result from two different experiments with different initial masses of sediment: $250 \mathrm{~g}$ and $500 \mathrm{~g}, \mathrm{n}=2.7, \mathrm{w}_{\mathrm{S}, 0}=115 \mathrm{~mm} / \mathrm{s}$ 
to hindered settling in the Stokes regime. For $n=2.39$, there is no influence of viscosity $(n=\mathrm{m})$ and settling is in the purely inertial regime.

In addition, $n^{\prime}$ must be adjusted to take account of the fact that Richardson and Zaki's formula is a best-fit line through a data set which is really scaling as $\left(1-\phi / \phi_{\max }\right)^{n^{\prime}}$ To do this, we re-write Eqs. 1 and 11 in logarithmic form, integrate the second-order Taylor expansion of the difference between these equations over the range $\phi=0$ to 0.5 and equate this difference to 0 (by analogy with the identification of the best fit undertaken by Richardson and Zaki). $\Delta n^{\prime}$ is that amount that $n$ 'must be reduced by for this integral to equate to 0 . It turns out that

$\Delta n^{\prime} \approx \frac{1}{6}(n-m)\left[\phi_{\max }-1\right] \approx-0.06(n-m)$

These considerations lead to an improved description of hindered settling for non-cohesive sediments, based on the Richardson-Zaki equation, but now corrected to account more properly for changes in viscosity as $\phi \rightarrow \phi_{\max }$. We conclude that the Richardson-Zaki experiments result in the following equation which holds for all $\phi_{\max }$,

$w_{s}=w_{s, 0}(1-\phi)^{m}\left(1-\phi / \phi_{\max }\right)^{n^{\prime}}$

where $n^{\prime}=0.62 n-1.46$ and $m=2.7-0.15 n$ and $n^{\prime}=0$ in the inertial regime and $n^{\prime} \approx 1.5$ in the Stokes regime which corroborates with the Krieger-Dougherty viscosity law.

\subsubsection{Application of the corrected Richardson-Zaki equation for non-cohesive sediments}

Figures 3 and 4 apply the corrected Richardson-Zaki equation (Eq. 18) to examples of the data from the original Richardson

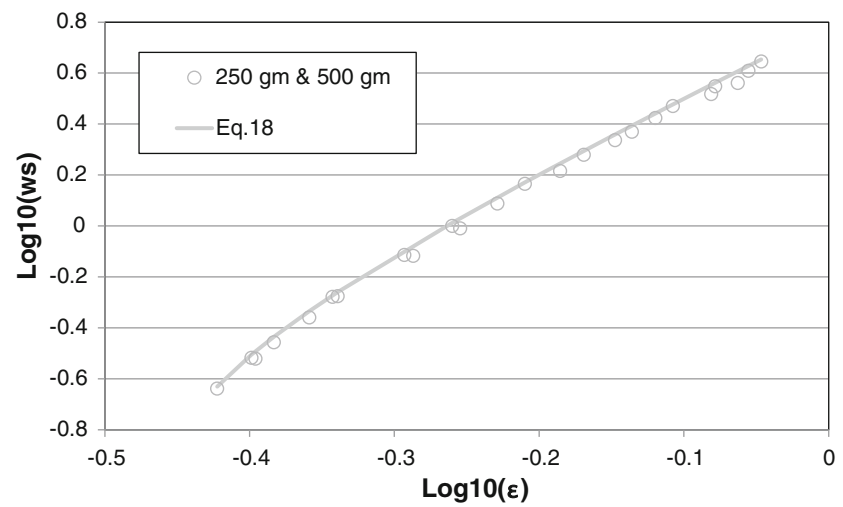

Fig. 3 Comparison of Eq. 18 with data from fluidisation tests by Richardson and Zaki (1954) using $0.51 \mathrm{~mm}$ ballotini. The units of $w_{s}$ used in the figure are in centrimetre per second as in the figure from the original paper. The figures show the change in behaviour of the hindered settling behaviour with changes in porosity $\varepsilon$. The tests using $250 \mathrm{~g}$ and 500 g of ballotini. $n=2.96, n=0.37, m=2.26, \phi_{\max }=0.66$, $w_{s, 0}=61 \mathrm{~mm} / \mathrm{s}$

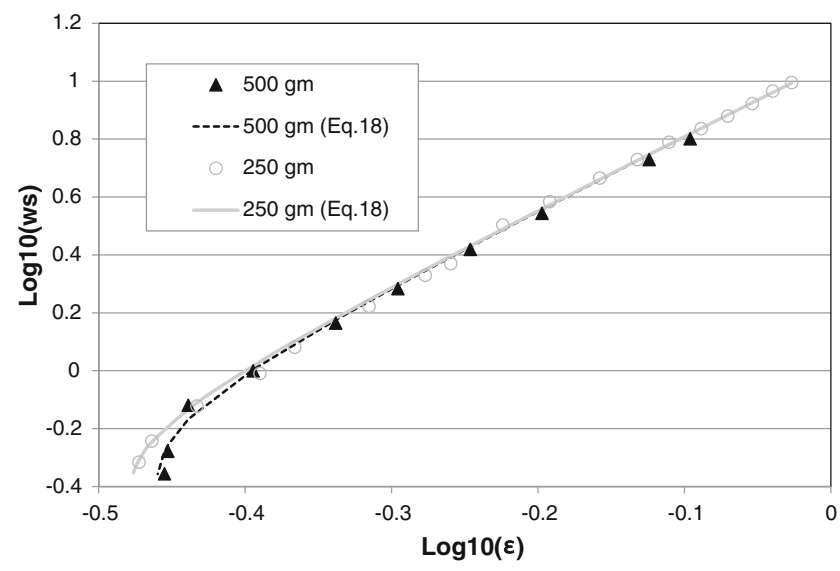

Fig. 4 Comparison of Eq. 18 with Richardson and Zaki's data from Fig. 2. $n=2.7, n^{\prime}=0.14, m=2.30, \phi_{\max }=0.655(250 \mathrm{~g})$ and 0.67 $(500 \mathrm{~g}), w_{s, 0}=115 \mathrm{~mm} / \mathrm{s}$

and Zaki (1954) experiments, including the example shown in Fig. 2. The corrected equation (Eq. 18) is shown to be an improvement on the original Richardson and Zaki formula (Eq. 11) as can be seen from a comparison of Figs. 2 and 4.

A comparison of Eq. 18 and measured hindered settling data for concentrated sediment concentrations from Baldock et al. (2004) is shown in Fig. 5. The model prediction is generated using Eq. 12 to generate the Richardson-Zaki exponent $n$, Eq. 18 to derive the hindered settling effect and Soulsby's (1997) equation for the settling of non-cohesive particles (Fig. 5a). The equivalent figure comparing the RichardsonZaki formula with the same data is shown in Fig. 5 b. It can be seen that the data shows significant departure from the Richardson-Zaki formula which is captured (although not perfectly) by Eq. 18. A comparison of the mean prediction errors (RMSE) of the two formula for this data shows that the error resulting from the application of Eq. 18 is approximately two thirds that of the application of the RichardsonZaki formula.

\subsection{Hindered settling of cohesive suspensions}

As we have seen in Sect. 2.2, the introduction of the $(1-\phi /$ $\phi_{\max }$ ) term into the hindered settling equation in Eq. 18 results in a better description of the settling of non-cohesive material. Equation 18 is of a similar form to hindered settling formulae for cohesive sediment (e.g. Toorman 1999; Winterwerp and Van Kesteren 2004; Camenen 2008; Camenen and Pham Van Bang 2011), with $\phi_{\max }$ now replaced by the gelling point of the concentrated suspension, $\phi_{\text {gel }}$, (the point when flocs form a space filling network), in order to account for the fact that flocs take up much more volume than a similar mass of noncohesive sediment. An additional adjustment is needed to adjust the term catering for the return current. This term changes from $(1-\phi)$ for non-cohesive sediment to $\left(1-\frac{\phi_{\text {max }}}{\phi_{g e l}} \phi\right)$ for cohesive sediment. This is because the return current is now a 
a

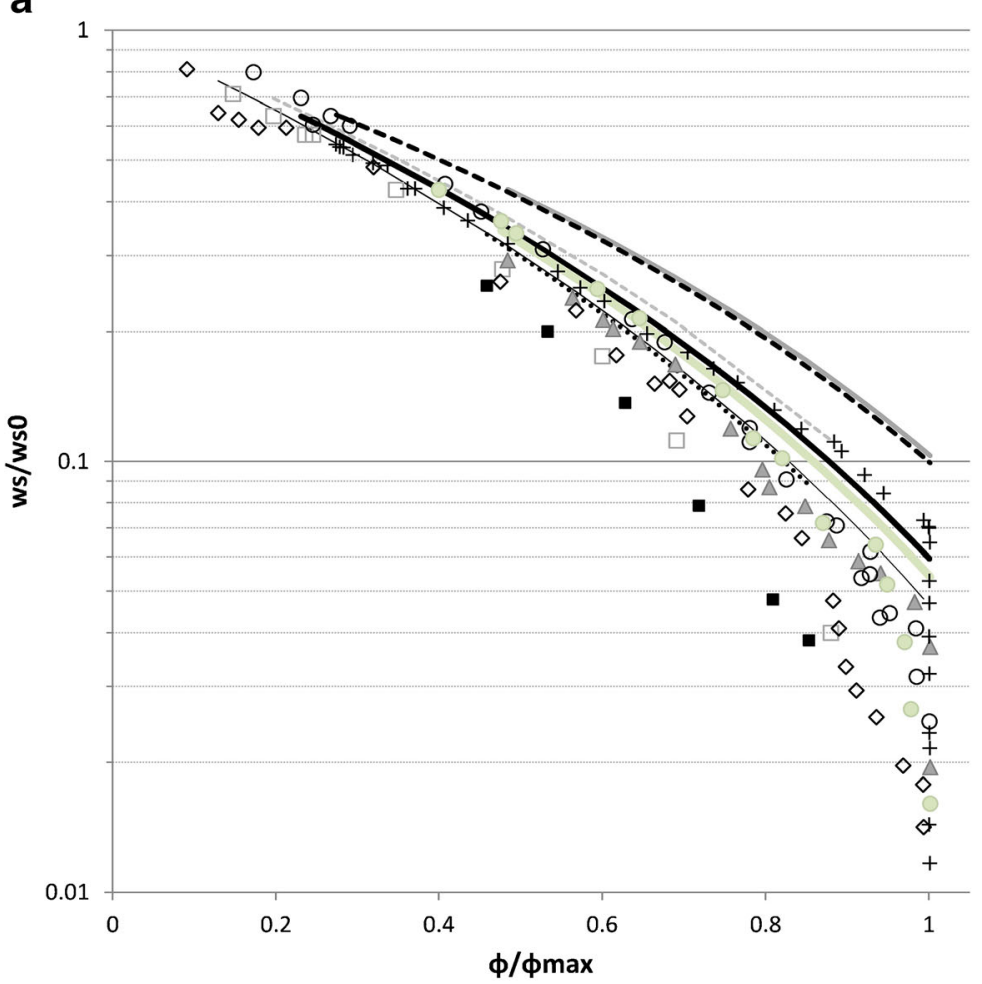

$\square \quad 0.2 \mathrm{~mm}$ beach sand (measured)

$---0.2 \mathrm{~mm}$ beach sand (predicted)

- $0.32 \mathrm{~mm}$ beach sand (measured)

..... $0.32 \mathrm{~mm}$ beach sand (predicted)

$\triangle \quad 2.4 \mathrm{~mm}$ gravel (measured)

$\mathbf{2} .4 \mathrm{~mm}$ gravel (predicted)

$\diamond \quad 0.35 \mathrm{~mm}$ glass (measured)

$0.35 \mathrm{~mm}$ glass (predicted)

○ $0.5 \mathrm{~mm}$ glass (measured)

$-0.5 \mathrm{~mm}$ glass (predicted)

$+\quad 1.85 \mathrm{~mm}$ glass (measured)

- - $1.85 \mathrm{~mm}$ glass (predicted)

$1.32 \mathrm{~mm}$ anthracite (measured)

$1.32 \mathrm{~mm}$ anthracite (predicted)

b

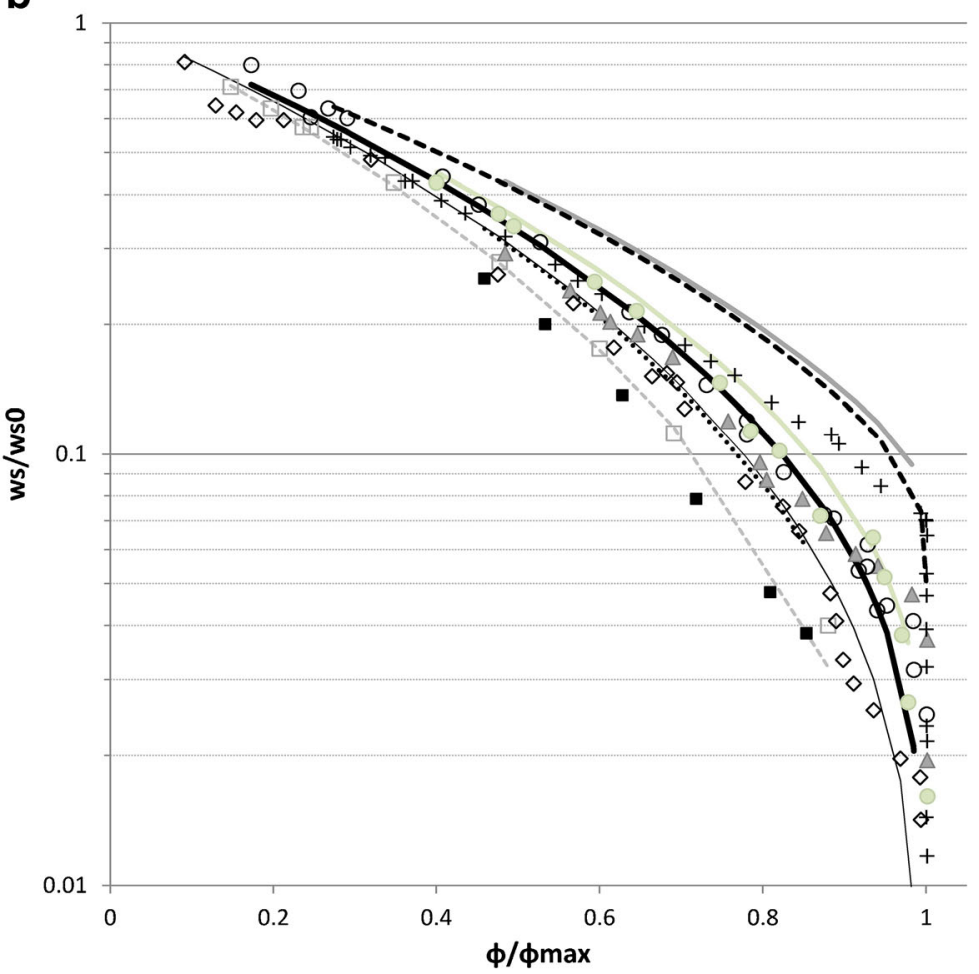

$\square \quad 0.2 \mathrm{~mm}$ beach sand (measured)

$0.2 \mathrm{~mm}$ beach sand (predicted)

- $0.32 \mathrm{~mm}$ beach sand (measured)

..... $0.32 \mathrm{~mm}$ beach sand (predicted)

$\Delta \quad 2.4 \mathrm{~mm}$ gravel (measured)

$2.4 \mathrm{~mm}$ gravel (predicted)

$\diamond \quad 0.35 \mathrm{~mm}$ glass (measured)

$0.35 \mathrm{~mm}$ glass (predicted)

○ $\quad 0.5 \mathrm{~mm}$ glass (measured)

$0.5 \mathrm{~mm}$ glass (predicted)

$+\quad 1.85$ mm glass (measured)

- - $1.85 \mathrm{~mm}$ glass (predicted)

$1.32 \mathrm{~mm}$ anthracite (measured)

$1.32 \mathrm{~mm}$ anthracite (predicted)

Fig. 5 Comparison of the Richardson-Zaki equation with data from Baldock et al. (2004). Equation 18 (top). Richardson-Zaki equation (bottom)

function of the volume taken by flocs (which have water trapped inside them) rather than just the volume of particles. $\frac{\phi_{\max }}{\phi_{\text {gel }}}$ represents a simple but approximate scaling factor for the increased volume taken up by these flocs. 
Assuming that cohesive settling is in the Stokes regime, then the cohesive version of Eq. 18 becomes

$w_{s}=w_{s, 0}(1-\phi)\left(1-\frac{\phi_{\max }}{\phi_{\text {gel }}} \phi\right)\left(1-\phi / \phi_{\text {gel }}\right)^{1.5}$

It is worth mentioning that the form of Eq. 19 is similar to that proposed by Camenen and Pham Van Bang (2011)

$w_{s}=w_{s, 0}(1-\phi)^{n / 2}\left(1-\phi_{\text {floc }}\right)^{\frac{n}{2}-1}\left(1-\phi_{\text {floc }} / \phi_{\text {floc }, \text { max }}\right)^{\phi_{\text {floc, } \text { max }}}$

where $\phi_{\text {floc, } \max }$ is the maximum volume concentration of flocs. The three terms are similar in form, but the exponents of each term are different.

\subsection{Hindered settling for $\phi$ close to $\phi_{\max }$ or $\phi_{g e l}$}

\subsubsection{Non-cohesive sediment suspensions}

Unlike the original Richardson-Zaki equation, the introduction of the $\left(1-\phi / \phi_{\max }\right)$ or $\left(1-\phi / \phi_{\text {gel }}\right)$ term into the hindered settling equation in Eq. 10 results in settling velocities which become smaller and smaller as $\phi \rightarrow \phi_{\max }$ and result in settling which never achieves the concentration $\phi_{\max }$ (or $\phi_{\text {gel }}$ ) (Kranenburg 1992; Dorrell and Hogg 2010). Kranenburg (1992) showed that for hindered settling formulae of the form $w_{s}=w_{s, 0}\left(1-\phi / \phi_{\max }\right)^{n}$, for initial concentrations of $\phi>2 /(n+$ $1)$, sediment never settles to the bed. This analysis, however, does not take into consideration that other factors come into play as $\rightarrow \phi_{\max }$. In particular, experiments investigating the fluidisation of sediments (i.e. at or near the limit as $\rightarrow \phi_{\max }$ ) have demonstrated that the settling velocity at $\phi=\phi_{\max }$ has a non-zero value given (in the laminar fine sediment regime) by Darcy's law (Baldock et al. 2004),

$w_{f}=k i$

where $w_{f}$ is the settling velocity associated with the point of fluidisation, $k$ is the permeability given by the KozenyCarman equation and $i$ is the hydraulic conductivity given in this case by $i=(s-1) /(1+e)=(s-1) \phi_{\max }$ where $s=\rho_{s} / \rho_{w}$ and $e$ is the void ratio. It can be shown (Baldock et al. 2004) that this results in the hindered settling velocity being no smaller than $0.018 \phi_{\max } w_{s, 0}$, where $\phi_{\max }$ is the maximum packing volume concentration of the non-cohesive sediment particles. Assuming $\phi_{\max } \approx 0.6$ (as did Baldock et al. 2004), this gives a lower limit for the reduction in sediment velocity of a factor of 0.011 for non-cohesive sediment. Obviously, as soon as sand particles reach the bed, their velocity becomes zero as the bed is rigid. However, just before this point or where due to fluidisation the sand skeleton is just supported by the upward flow, the settling velocity is given by Eq. 21 .

\subsubsection{Cohesive sediment suspensions}

In the case of cohesive sediment, permeability again ensures that the settling velocity never reaches zero for values of $\phi$ less than $\phi_{\text {gel }}$. In cohesive sediments, however, the settling particles (flocs) deform as water is squeezed out of them and an approach is required which takes account of this. By assuming a constant fractal dimension in the consolidating bed, and for the initial consolidation phase where the effective stresses are negligible, the settling velocity due to permeability can be approximated as (Merkelbach 2000; Merckelbach and Kranenburg 2004)

$w_{f}=\frac{\rho_{s}-\rho_{w}}{\rho_{w}}\left(\phi_{m}+\phi_{s}\right) K_{k}\left(\frac{\phi_{m}}{1-\phi_{s}}\right)^{-\frac{2}{3-\rho_{f}}}$

where $K_{k}$ (with units of metre per second) is a function of the shape and size of the constituent sediment particles, the fractal dimension and the sediment concentration (Merckelbach 2000). In practice, $K_{k}$ is taken as an empirical constant determined from consolidation experiments (e.g. Merckelbach 2000). $D_{f}$ is the fractal dimension of flocs in the bed, and $\phi_{m}$ and $\phi_{s}$ are the volumetric concentrations of mud and sand.

Camenen and Pham Van Bang (2011) proposed a method for establishing a smooth transition from the hindered settling phase to the permeability phase of consolidation. This essentially involves identifying the value of $\phi$ where the derivative of $w_{f}$ in Eq. 22 with respect to $\phi$ matches the corresponding derivative of Eq. 20 and then setting $K_{k}$ so that $w_{f}=w_{\mathrm{s}}$. In this paper, we propose a simple method whereby the settling velocity is taken to be the maximum of either Eq. 19 or 22.

Figure 6 shows a plot of $\frac{w_{s}}{w_{s, 0}}$ against $\phi / \phi_{\text {gel }}$ using data of settling cohesive sediment from Dankers (2006). The plot shows the results of settling experiments using kaolinite in settling columns $40 \mathrm{~cm}$ high and diameter $7 \mathrm{~cm}$ (Dankers 2006). The value of $D_{f}$ varies for each experiment but for the average value of $f, D_{f} \approx 2.41$. Dankers' data suggests $K_{k} \approx 10^{-9}$.

\subsection{Approaches to polydisperse sedimentation}

\subsubsection{Theoretical approaches based on original work by Batchelor}

Davis and Gecol (1994), based on work by Batchelor (1982) and Batchelor and Wen (1982), developed the following formula for the settling velocity of fraction $i$ in a polydisperse suspension

$W_{s}^{i}=w_{s, 0}^{i}(1-\phi)^{-S_{i i}}\left(1+\sum_{j \neq 1}^{m}\left(S_{i j}-S_{i i}\right) \phi_{j}\right)$

where $W_{s}^{i}$ is the polydisperse hindered settling velocity and $S_{i i}$ is -5.6 for non-colloidal particles and -6.5 for colloidal 
Fig. 6 Comparison of Eqs. 19 and 22 with data from Dankers (2006). The data and model results in circles are indicative only as the gelling concentration for these experiments was not measured. The grey line indicates a broad brush typical trend in the data

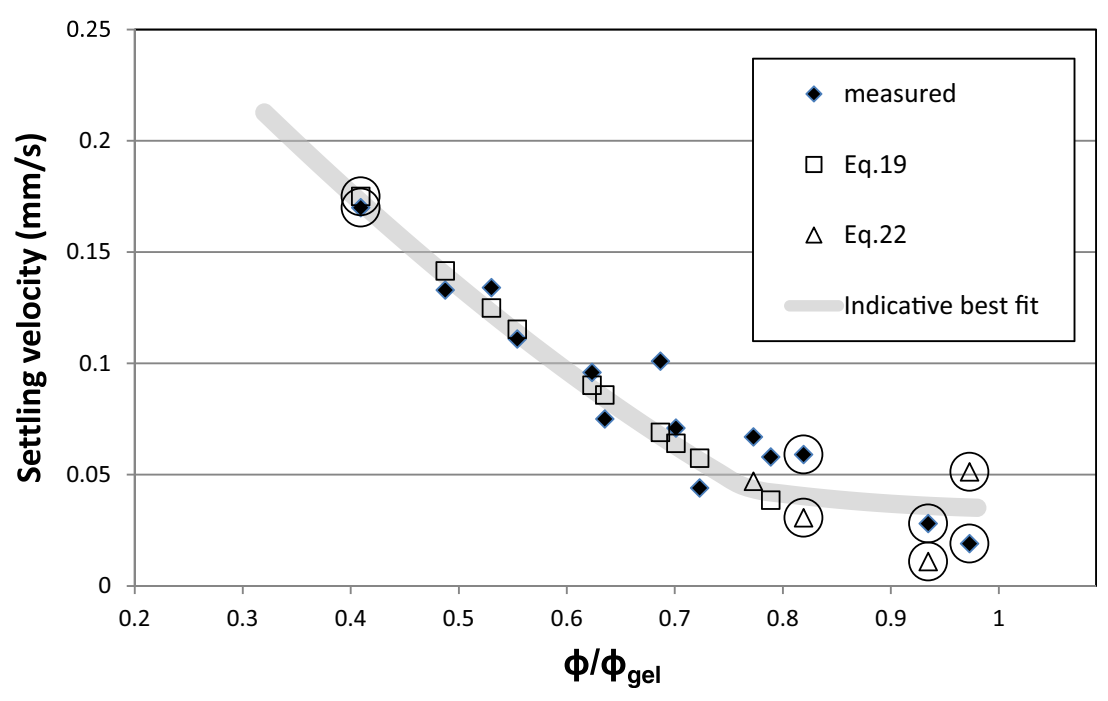

particles, and Davis and Gecol (1994) correlated the numerical solutions of Batchelor and Wen (1982) to give

$S_{i j}=-3.5-1.1 \lambda_{i j}-1.02 \lambda^{2}-0.002 \lambda^{3}$ for non-colloidal particles

$S_{i j}=-3.42-1.96 \lambda-1.21 \lambda^{2}-0.013 \lambda^{3}$ for colloidal particleswhere $\lambda_{i j}=d_{j} / d_{i \text {. }}$

The strengths of the Davis and Gecol formula were that it extended the work by Batchelor to higher concentrations and that, within the Stokes regime, it provided satisfactory estimates of the settling of polydisperse suspensions without recourse to empiricism in the selection of $n$. However, this equation does not adequately account for the differences in the return flow of fluid caused by downward movement of different sediment fractions because it does not account for the difference in density between particle fractions (Berres et al. 2005; Ha and Liu 2002). In addition, Berres et al. (2005) and Burger et al. (2002) identified that the Davis and Gecol formula is unstable (that is, they result in non-hyperbolic solutions which show oscillating behaviour) for some bidisperse systems.

Ha and Liu (2002) attempted to improve some of the deficiencies of the Davis and Gecol formula by using correlations for $S_{i j}$ developed by Liu (2000) which accounted for both size and density differences between particle fractions. The values of $S_{i j}$ were derived to be

$S_{i j}=-2.5-\left(\lambda_{i j}+3 \lambda_{i j}+1-\frac{1.87 \lambda_{i j}}{1+0.0024 \lambda_{i j}^{2}}\right) \gamma_{i j}$

where $\lambda_{i j}=d_{j} / d_{i}$ and $\gamma_{i j}=\left(\rho_{j}-\rho_{w}\right) /\left(\rho_{i}-\rho_{w}\right)$ are the ratios of the particle diameters and particle densities, respectively.

For generalised polydisperse, the formula has limited use since its validity is restricted to the Stokes regime. Moreover, Van and Pham Van Bang (2013) identified instability issues with the $\mathrm{Ha}$ and Liu approach which are similar to those for the Davis and Gecol formula.

\subsubsection{Winterwerps approach}

Winterwerp $(1999,2002)$ developed an equation for the hindered settling of cohesive sediment flocs

$w_{s}=w_{s, 0} \frac{\left(1-\phi_{m} / \phi_{\text {gel }}\right)^{k}\left(1-\phi_{m}\right)}{1+2.5 \phi_{m} / \phi_{\text {gel }}}$

This equation was further developed by Winterwerp and van Kesteren (2004) for suspensions of sand and mud where $\phi_{s} \ll \phi_{m}$,

$W_{s}^{m}=w_{s, 0}^{m} \frac{\left(1-\phi_{m} / \phi_{\text {gel }}-\phi_{s}\right)^{k}\left(1-\phi_{m}-\phi_{s}\right)}{1+2.5 \phi_{m} / \phi_{\text {gel }}}$

$W_{s}^{s}=\left(w_{s, 0}^{s}-\phi^{m} w_{s, 0}^{m}\right) \frac{\left(1-\phi_{m} / \phi_{g e l}-\phi_{s}\right)^{k}}{\left(1-\phi_{m}\right)} \frac{\left(1-\phi_{m}-\phi_{s}\right)}{\left(1+2.5 \phi_{m} / \phi_{g e l}\right)}$

$k$ is an undefined parameter, but Dankers (2006) provided evidence that $k \approx 2$, based on analysis of Kynch theory and settling fronts.

This equation is really only valid for relatively low concentrations because the viscosity term $\left(1+2.5 \phi / \phi_{\text {gel }}\right)^{-1}$ is only valid for dilute suspensions. In reality, the viscosity varies as $(1-\phi /$ $\left.\phi_{\max }\right)^{-2}$ (Quemada 1977) or $\left(1-\phi / \phi_{\max }\right)^{-2.5 \phi_{\max }}$ (Krieger and Dougherty 1959). The equation perhaps has the flexibility to cater for scenarios outside the Stokes regime (e.g. through variation in $k$ ), but there is no systematic determination of $k$ for different particle Reynolds numbers, and such an exercise may be compromised to some extent by the (inherent) assumption of dilute concentration. The validation of Eq. 26a, b (Dankers 2006), based on settling column measurements, is unsatisfactory because the turning on of the camera was not systematically timed relative to the release of the clay and sand. The measurement data therefore can only be used qualitatively. 
Te Slaa et al. (2013) improved Eq. 25 by replacing the Einstein viscosity term $\left(1+2.5 \phi / \phi_{\text {gel }}\right)^{-1}$ by the Krieger and Dougherty term $\left(1-\phi / \phi_{\max }\right)^{-2.5 \phi_{\max }}$, but as yet, there has been no formal validation of this equation through modelling and comparison with observations.

\subsubsection{Wang et al.'s approach}

Wang et al. (1995) attempted to formulate an expression to describe the settling velocity of non-cohesive sand particles within clay suspensions, proposing a purely empirical equation based on the and Maude and Whitmore (1958) formulae (similar to that of Richardson and Zaki) and a formula for viscosity of clay suspensions by Wang et al. (1994)

$\frac{W_{s}}{w_{s, 0}}=\left(1-\phi_{S}\right)^{n}\left(1-K \phi_{\text {clay }}\right)^{2.5}$

where $K$ is an empirical coefficient to be determined. Equation 27 is essentially the application of the Richardson-Zaki formula twice - once for the mud (clay) content and once for the sand content-but there is little guidance as to the values of $n$ and $K$, and these are empirical values to be fitted.

\subsubsection{Masliyah Lockett and Bassoon equation}

The MLB formula represents a fully generalised version of the Richardson-Zaki equation and is given by

$W_{s}^{i}=(1-\phi)^{n-2}\left(w_{s, 0}^{i} \frac{\rho_{i}-\rho_{\text {susp }}}{\rho_{i}-\rho_{w}}-\sum_{j=1}^{N} \frac{\rho_{j}-\rho_{\text {susp }}}{\rho_{i}-\rho_{w}} \phi_{j} w_{s, 0}^{j}\right)$

where $\rho_{\text {susp }}=(1-\phi) \rho_{w}+\sum_{j}^{N} \phi_{i} \rho_{i}, \rho_{i}$ is the density of the $i$ th sediment fraction, $\rho_{w}$ is the density of water and $n$ is the exponent of the Richardson and Zaki equation. In this form, the MLB is valid beyond the Stokes regime. The second term in the MLB formula includes the effect of buoyancy and return currents. This becomes immediately obvious if $\rho_{i}$ becomes uniform for all particles when Eq. 27 becomes

$w_{s}^{i}=(1-\phi)(1-\phi)^{n-2}\left(w_{s, 0}^{i}-\sum_{j=1}^{N} \phi_{j} w_{s, 0}^{j}\right)$

\section{Numerical model application}

\subsection{Numerical model}

\subsubsection{Modified MLB equation}

In this study, we use the modified Richardson and Zaki equations (Eqs. 18 and 19, as discussed in Sects. 2.2 and 2.3) in polydisperse MLB form. It will be shown that this modification results in the reduction in the extent of the empiricism observed by many researchers of polydisperse settling (e.g. Wang et al. 1995; Van and Pham Van Bang 2013). The modified MLB equation (henceforth referred to as mMLB) is used because it can be used for real mixtures of sand and silt and clay with varying particle size distribution; it is valid for the Stokes and inertial regimes and the transition between them. The set of equations used for the polydisperse hindered settling is summarised below in Eqs. 30-36. We will use an upper case $W$ to denote the settling velocity including all the polydisperse hindered settling effects and a lower case $w_{s}$ otherwise.

$W_{s}^{i}=w_{s}^{i}-\sum_{j=1}^{N} \phi_{j} w_{s}^{j}$

where for the cohesive fraction $(i=1)$

$w_{s}^{i}=\max \left(w 1_{s}^{i}, w 2_{s}^{i}\right)$

where

$w 1_{s}^{i}=w_{s, 0}^{i}(1-\phi)\left(1-\frac{\phi_{\max }}{\phi_{\text {gel }}} \phi\right)\left(1-\phi / \phi_{\text {gel }}\right)^{1.5}$

and

$w 2_{s}^{i}=\frac{\rho_{s}-\rho_{w}}{\rho_{w}}\left(\phi_{m}+\phi_{s}\right) K_{k}\left(\frac{\phi_{m}}{1-\phi_{s}}\right)^{-\frac{2}{3-D_{f}}}$

and for the non-cohesive fractions $(i=2, \ldots, N)$

$w_{s}^{i}=\max \left(w 1_{s}^{i}, w 2_{s}^{i}\right)$

where

$$
\begin{aligned}
w 1_{s}^{i} & =w_{s, 0}^{i}(1-\phi)^{m}\left(1-\phi / \phi_{\max }\right)^{n^{\prime}} \text { with } n^{\prime} \\
& =0.62 n-1.46 \text { and } m=2.7-0.15 n
\end{aligned}
$$

and

$w 2_{s}^{i}=0.018 \phi_{\max } w_{s, 0}^{i}$

The unhindered settling velocity $w_{s, 0}^{i}$ for cohesive sediment $(i=1)$ used in the case studies below was calculated based on data given in the experiment (e.g. the rate of change in height of the water-sediment interface and the initial concentration) or through calibration.

The non-hindered settling velocity $w_{s, 0}^{i}$ for non-cohesive sediment grains $(i=2, \ldots, N)$ was derived using Eq. 4 . 


\subsubsection{Numerical approach}

In the remainder of this paper, we use the considerations above to solve the Kynch-like equation (Toorman 1996, 1999; Winterwerp and Van Kesteren 2004; Camenen and Pham Van Bang 2011)

$$
\frac{\partial \phi}{\partial t}+\frac{\partial S}{\partial z}=\frac{\partial}{\partial z}\left[\left(D_{s}+D_{H}+\Gamma_{T}+\Gamma_{c}\right) \frac{\partial \phi}{\partial z}\right]
$$

where $S=W_{s} \phi$ is the sediment flux and $W_{s}=W_{s}\left(w_{s, 0}, \phi_{1}, \phi_{2}, \ldots, \phi_{N}\right) . W_{s}$ is positive when settling is downwards. The model solves the settling of sediment fraction $i$ at $z_{k}$ where $k=1, M$ and $i=1, N$. The sediment flux for the $i$ th fraction at the $k$ th layer is given by (Scheme 2, Burger et al. 2008)

$S_{k}^{i}=\phi_{k}^{i} \max \left(0, W_{s k+1}^{i}\right)+\phi_{k+1}^{i} \min \left(0, W_{s k+1}^{i}\right)$

The diffusion term on the right-hand side of Eq. 36 accounts for a number of different diffusion mechanisms. The first, $D_{s}$, represents the molecular diffusion (for instance which contributes to Brownian motion). This diffusion is negligible except for sediment particles of very small size (less than a micron or so in diameter). The second term, $D_{H}$, represents the diffusion caused by the randomly fluctuating motion induced by the surrounding particles (Koch and Shaqfeh 1991; Yin and Koch 2008; Mucha and Brenner 2003). This term is usually small but (in the absence of eddy diffusivity) not necessarily negligible. This term contributes to the broadening of fronts of settling fractions in settling columns although the effect of polydispersivity is likely to be more significant (Bergougnoux et al. 2002; Nguyen and Ladd 2005). $\Gamma_{T}$ is the eddy diffusivity. In sedimenting coastal systems, this eddy diffusivity term will dominate, but in settling columns (which are the data sets used to test hindered settling in this paper), this source of diffusion is negligible. $\Gamma_{c}$ is a diffusion coefficient which dominates in the final stages of consolidation when there are effective stresses in the soil. This paper does not consider this final phase of consolidation as it concentrates on the hindered settling phase, and so, $\Gamma_{c}$ can be considered to be negligible. Thus, the diffusion in Eq. 37 is equal to $D_{H}$ for the laboratory tests considered in this paper and is small.

Equation 37 is solved using a first-order upwind scheme, with a central difference scheme for the diffusion operator as described below. The equation is solved using the method of substitution. The method uses explicit Euler time stepping. An additional corrector step is included in the model to ensure monotonicity of the concentration profile. This ensures that if there is a positive (total) concentration gradient with elevation, sufficient mass is transferred between model layers to correct this anomaly. This step prevents instabilities arising near interfaces. Except where this correction is applied, there is no numerical diffusion in the model. Time steps used varied between $5 \times 10^{-4}$ and $10^{-1} \mathrm{~s}$. The model is only suitable to describe hindered settling for concentrations in the hindered settling regime and the (start of the) permeability settling regime. Consolidation is not represented in the model except near to the gelling point where settling due to permeability may exceed that of hindered settling.

The distribution of suspended sediment in the vertical is modelled as Eq. 37, but in terms of mass, rather than volume, concentration,

$\frac{\partial c_{k}^{i}}{\partial t}+\frac{\partial s_{k}^{i}}{\partial z}-\frac{\partial}{\partial z}\left[D_{H, k} \frac{\partial c_{k}^{i}}{\partial z}\right]=0$

where $c_{k}^{i}$ is the suspended sediment concentration of the $i$ th sediment fraction at the $k$ th vertical layer, $D_{H, k} i s$ the hydrodynamic diffusivity at the $k$ th vertical layer and $s_{k}^{i}$ is the settling flux of the $i$ th sediment fraction at the $k$ th vertical layer given by $S_{k}^{i}=c_{k}^{i} \max \left(0, W_{s k+1}^{i}\right)+c_{k+1}^{i} \min \left(0, W_{s k+1}^{i}\right)$ and $W_{s, k}^{i}$ is the settling velocity of the $i$ th sediment fraction at the $k$ th vertical layer. For each of the sediment fractions, Eq. 39 is solved in matrix form,

$F C_{k}=G$

where $\boldsymbol{F}$ is a tridiagonal matrix with components which are given as follows (41):

$$
\begin{aligned}
k=1 & F_{k-1, k}=0 \\
F_{k+1, k}= & -D_{H, k} d t /\left[\left(z_{k}\right)\left(z_{k+1}\right) / 2\right] \\
F_{k, k}=1 & +D_{H, k} d t /\left[\left(z_{k}\right)\left(z_{k+1}\right) / 2\right] \\
k=2 \quad F_{k-1, i}= & -D_{H, k-1} d t /\left[\left(z_{k}-z_{k-1}\right)\left(z_{k}\right) / 2\right] \\
F_{k+1, k}= & -D_{H, k} d t /\left[\left(z_{k}-z_{k-1}\right)\left(z_{k+1}-z_{k-1}\right) / 2\right] \\
F_{k, k}=1 & +D_{H, k-1} d t /\left[\left(z_{k}-z_{k-1}\right)\left(z_{k}\right) / 2\right] \\
& +D_{H, k} d t /\left[\left(z_{k}-z_{k-1}\right)\left(z_{k+1}-z_{k-1}\right) / 2\right] \\
k=3, m-1 & \\
F_{k-1, i}= & -D_{H, k-1} d t /\left[\left(z_{k}-z_{k-1}\right)\left(z_{k}-z_{k-2}\right) / 2\right] \\
F_{k+1, k}= & -D_{H, k} d t /\left[\left(z_{k}-z_{k-1}\right)\left(z_{k+1}-z_{k-1}\right) / 2\right] \\
F_{k, k}=1 & +D_{H, k-1} d t /\left[\left(z_{k}-z_{k-1}\right)\left(z_{k}-z_{k-2}\right) / 2\right] \\
& +D_{H, k} d t /\left[\left(z_{k}-z_{k-1}\right)\left(z_{k+1}-z_{k-1}\right) / 2\right] \\
k=m \quad & -D_{H, k-1} d t /\left[\left(z_{k}-z_{k-1}\right)\left(z_{k}-z_{k-2}\right) / 2\right] \\
\left.F_{k-1, k}\right] & \\
F_{k+1, k}= & 0 \\
F_{k, k}= & 1+D_{H, k-1} d t /\left[\left(z_{k}-z_{k-1}\right)\left(z_{k}-z_{k-2}\right) / 2\right]
\end{aligned}
$$


and $\boldsymbol{G}$ is the single column matrix given by

$$
k=1 \quad G_{k}=c_{k}^{i}+\left[s_{k}^{i} d t\right] /\left(z_{1}\right)
$$

$k=2, m-1 \quad G_{k}=c_{k}^{i}+\left[s_{k}^{i} d t\right] /\left(z_{k}-z_{k-1}\right)-\left[s_{k-1}^{i}\right] /\left(z_{k}-z_{k-1}\right)$

$k=m \quad G_{k}=c_{k}^{i}-\left[s_{k-1}^{i} d t\right] /\left(z_{k}-z_{k-1}\right)$

\subsubsection{Data used for application of the model}

Although there are a number of laboratory measurements of non-cohesive polydisperse laboratory studies (e.g. Mirza and Richardson 1979; Kothari 1981; Al-Naafa and Selim 1989; Amy et al. 2006), the number of studies involving polydisperse suspensions with non-cohesive and cohesive fractions are much more restricted. Initially, results from Amy et al. (2006) are used to show the performance of the model for non-cohesive polydisperse settling. The results of Van and Pham Van Bang (2013) and Te Slaa et al. (2013) are used to investigate the model behaviour for mixed sediments.

\subsection{Amy et al. (2006) non-cohesive settling column experiments}

Amy et al. (2006) undertook a series of settling column experiments to investigate the settling behaviour of particulate suspensions. A range of suspensions was tested comprising saline solution and non-cohesive glass-ballotini sand of particle size 35.5-250 $\mu \mathrm{m}$ (median $100 \mu \mathrm{m}$ ) and cohesive kaolinite clay of particle size $0.3-35.5 \mu \mathrm{m}$ (median $8.2 \mu \mathrm{m}$ ). The volumetric concentration of sand in these solutions varied up to 0.6 and that of the clay up to 0.15 . The tubes used were $7.2 \mathrm{~cm}$ in diameter and were filled to a height of $22.7 \mathrm{~cm}$. All experiments were left for $12 \mathrm{~h}$ to settle and then were frozen at $-25{ }^{\circ} \mathrm{C}$ for a further $25 \mathrm{~h}$. Samples of the frozen tube deposit were then analysed along the centre of the tube. Observations of the variation in the $\mathrm{d} 10, \mathrm{~d} 50$ and $\mathrm{d} 90$ percentiles of particle diameter were undertaken. Figure 7 shows comparison of the deposits resulting from experiments with initial non-cohesive sand concentrations of $\left(\phi_{\mathrm{s}}=\right)$ 0.1, 0.2 and 0.4 with the results of the mMLB model. The mMLB was run 28 fractions with the particle size distribution shown in Fig. 8 and $D_{H}=0$. Figure 7 shows that the model performs well in predicting the $\mathrm{d} 10, \mathrm{~d} 50$ and $\mathrm{d} 90$ percentiles of the particle size through the deposit although the $\mathrm{d} 90$ is under-predicted near the surface for the higher initial concentrations. The cause for this is considered to be associated with the relatively simple firstorder model struggling with the high concentration gradients found close to the sand bed (see Sect. 3.4) but may also be due to the particle size distribution being less well resolved in the surface deposits. a

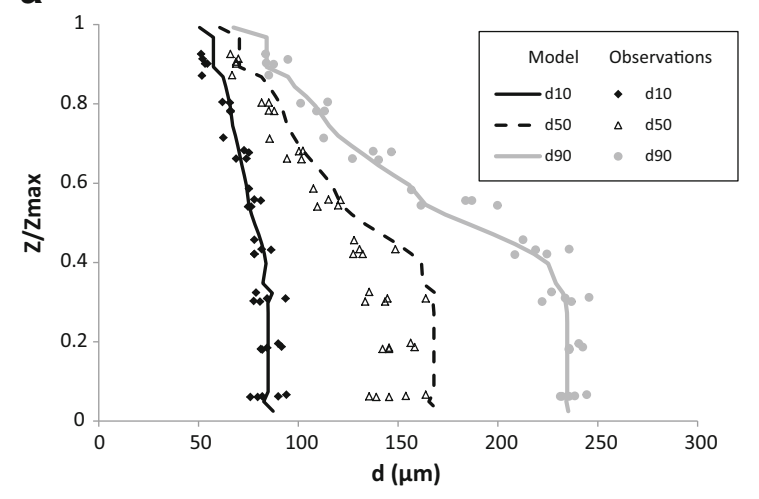

b
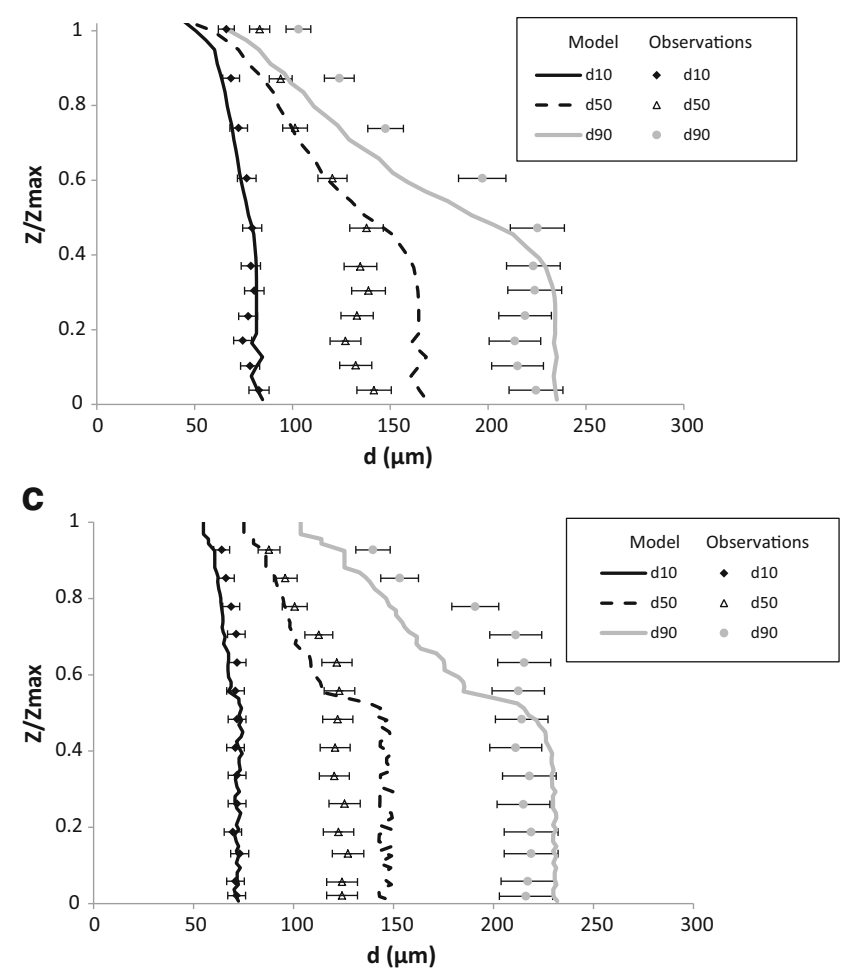

Fig. 7 Predicted and measured variation in d10, d50 and d90 with normalised height $\left(Z / Z_{\max }\right)$ of settled deposit (Amy et al. 2006). Five repeated experiments with $\phi_{\mathrm{s}}=0.1, \phi_{\mathrm{m}}=0.0$ (top). Experiment with $\phi_{\mathrm{s}}=0.2, \phi_{\mathrm{m}}=0.0$ (middle). Experiment with $\phi_{\mathrm{s}}=0.4, \phi_{\mathrm{m}}=0.0$ (bottom). Data from Amy et al. (2006); error bars in middle and bottom figures are Dorrell et al. (2011)

\subsection{Te Slaa et al. (2013) experiments}

Te Slaa et al. (2013) undertook settling column experiments on natural (mixed) sediments from the Yangtze and Yellow rivers. The columns used were $1.3 \mathrm{~m}$ in height with an internal diameter of $0.1 \mathrm{~m}$. Measurements of concentration through depth were made using electrical conductivity, and for some experiment, the vertical sediment profile was analysed for particle size. We show results here for experiments B8, C5, J6 and M5 as set out in Table 1. 
Fig. 8 Particle size distribution in the Amy et al. (2006) experiments

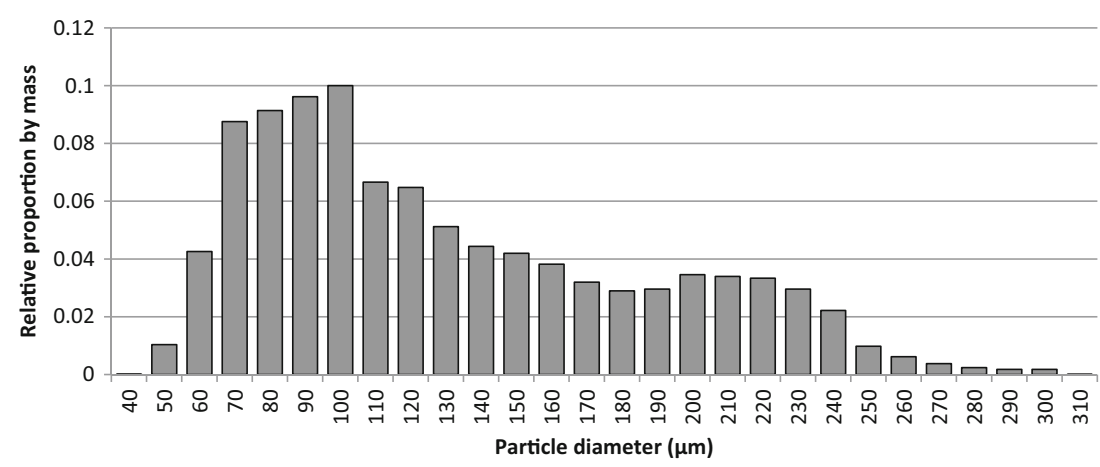

The results of Te Slaa et al. (2013) are presented in the form of the measured volumetric concentration at the time $t_{2}$, when the granular (silt/sand) particles were all deposited, time $t_{3}$, when the gelling point is obtained, and $t_{\text {end }}$ at the end of the test. In addition, the change in percentage of clay/silt/sand and in d50 with height in the settled deposit is also presented.

The model predictions of volumetric concentration at times $t_{\text {end }}$ and of the variation of percentage clay/silt/ sand and d50 with height are shown for tests B8, C5 and J6 in Figs. 9, 10 and 11. The model runs use a simple engineering approach for the particle diffusion with $D_{H}=10^{-6}(1-\phi)$ for $\phi<\phi_{\max }$ and $D_{H}=0$ otherwise. The mMLB model was run for 7 to 12 sediment fractions ( 1 cohesive clay fraction; 4-6 silt fractions, 10 $60 \mu \mathrm{m}$; and 2-5 sand fractions $105-300 \mu \mathrm{m}$ ) depending on the particle size distribution of the mud.

For the viscosity term, $\phi_{\max }$ for the granular fractions was taken in the model as $1600 \mathrm{~kg} / \mathrm{m}^{3}\left(\phi_{\max }=0.6\right)$. The values of $c_{\text {gel }}$ recorded by $\mathrm{Te}$ Slaa et al. varied over the range of $107-240 \mathrm{~kg} / \mathrm{m}^{3}$ for the Yangtze River mud and $81-184 \mathrm{~kg} / \mathrm{m}^{3}$ for the Yellow River mud depending on the method of calculation. The values of settling velocity $w_{s, 0}$ and of $c_{g e l}$ for the cohesive fraction were derived from trial and error in the model runs (B8 $0.25 \mathrm{~mm} / \mathrm{s}$ and $136 \mathrm{~kg} / \mathrm{m}^{3}$; c5 $0.23 \mathrm{~mm} /$ $\mathrm{s}$ and $200 \mathrm{~kg} / \mathrm{m}^{3} ; \mathrm{J} 60.2 \mathrm{~mm} / \mathrm{s}$ and $150 \mathrm{~kg} / \mathrm{m}^{3}$ ). The effect of varying $c_{g e l}$ can be complex, but typically larger values tended to increase the depth of deposit of silt and clay above the sandier deposits and to reduce the variation of particle size in this deposit.

Table 1 Test data from Te Slaa et al. (2013) experiments

\begin{tabular}{lllll}
\hline Test & $\%$ Clay & $\%$ Silt & $\%$ Sand & Total volume concentration $\left(\mathrm{kg} / \mathrm{m}^{3}\right)$ \\
\hline B8 & 9 & 86 & 5 & 401 \\
C5 & 8 & 62 & 30 & 367 \\
J6 & 7 & 53 & 40 & 488 \\
\hline
\end{tabular}

It can be seen from the results of Figs. 9, 10 and 11 that the bottom $10-30 \mathrm{~cm}$ of the deposit in tests B8, C5
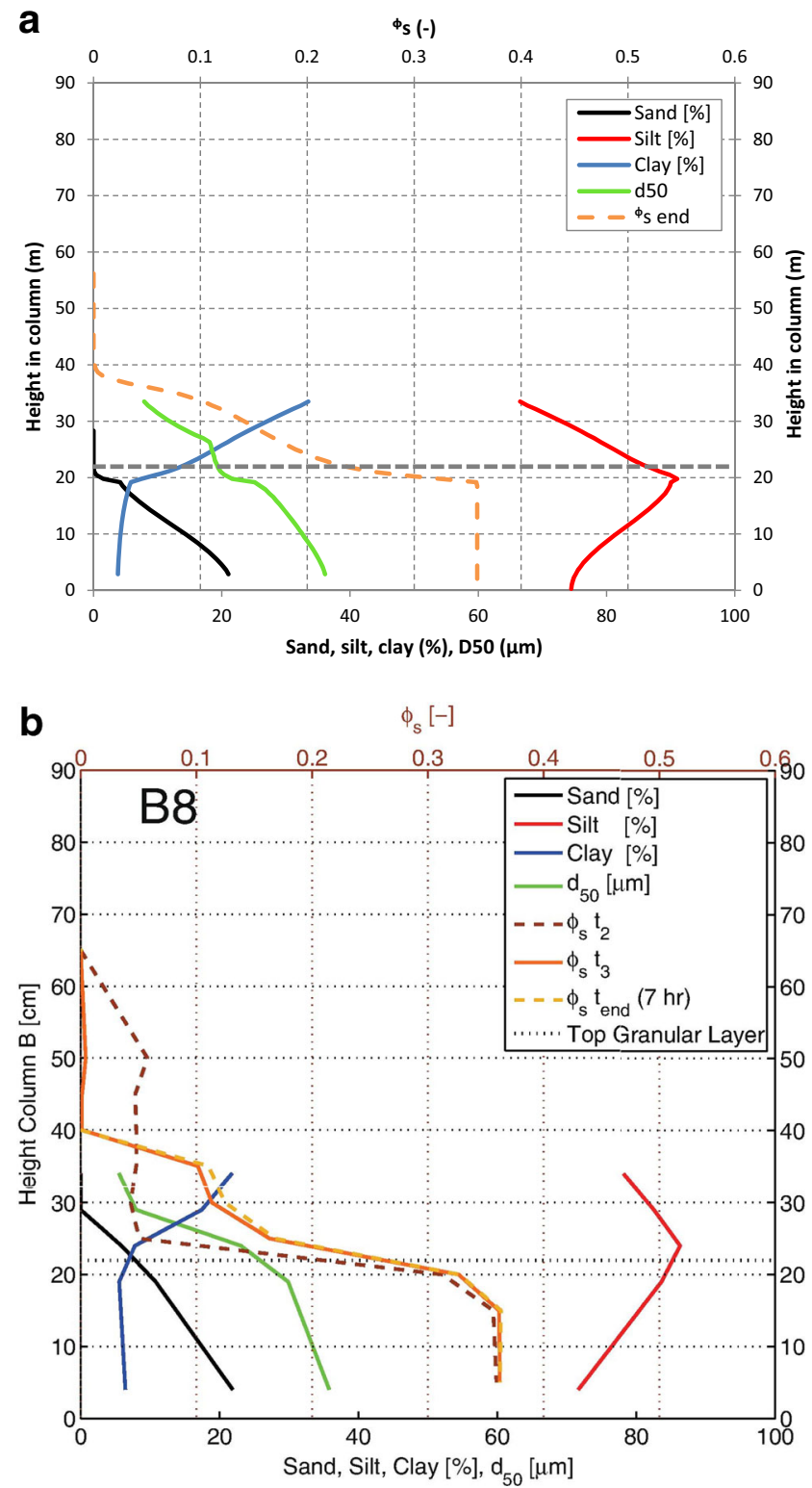

Fig. 9 Predicted (top) and measured (bottom) variation in particle size distribution and volumetric concentration, test B8. Data from Te Slaa et al. (2013). Bottom figure shown with the kind permission of Springer 


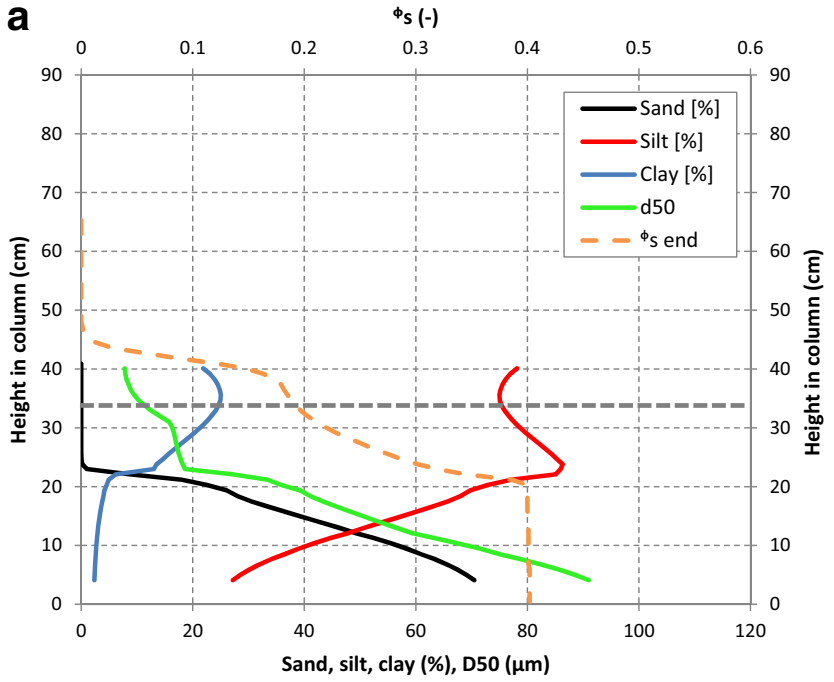

b

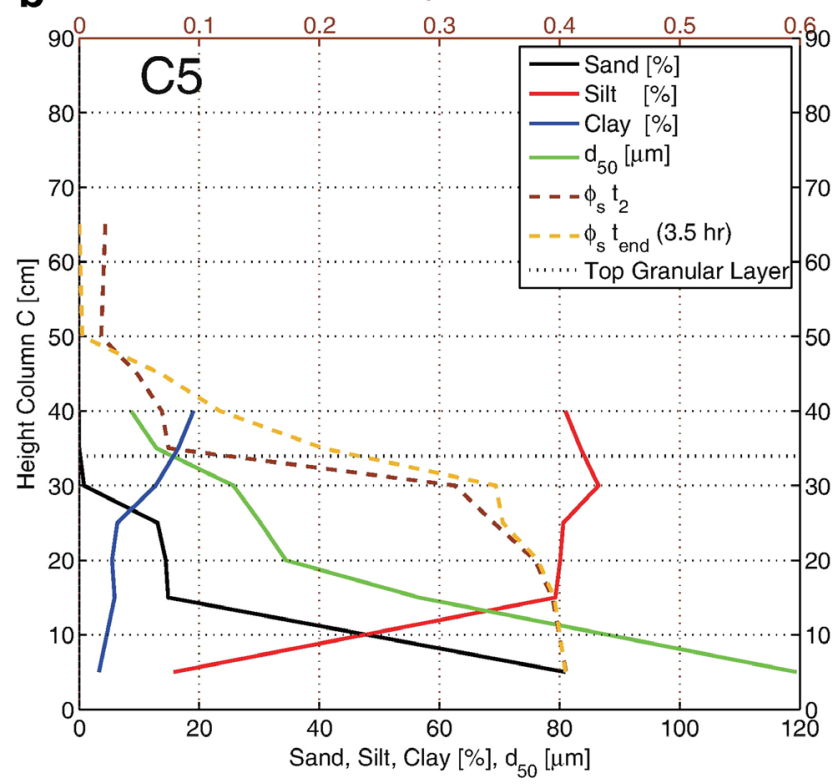

Fig. 10 Predicted (top) and measured (bottom) variation in particle size distribution and volumetric concentration, test C5. Data from Te Slaa et al. (2013). Bottom figure shown with the kind permission of Springer

and J6 forms a deposit of constant concentration (B8 $\phi \approx 0.37, \mathrm{c} 5 \phi \approx 0.4, \mathrm{~J} 6 \phi \approx 0.5)$ which contrasts with the gel point of the cohesive fraction (B8, c5, J6 $\phi_{\text {gel }} \approx 0.05-$ $0.075)$ and the maximum packing of the granular fraction $\left(\phi_{\max } \approx 0.60 .6\right)$. These deposit densities arise because of a more complex volumetric interaction between clay, silt and sand particles which is not a priori calculated by the model. For the test runs, the density of deposited material in each model run was limited to these observed values.

Figures 9, 10 and 11 show that the model performs well in reproducing the observed settling behaviour for natural a

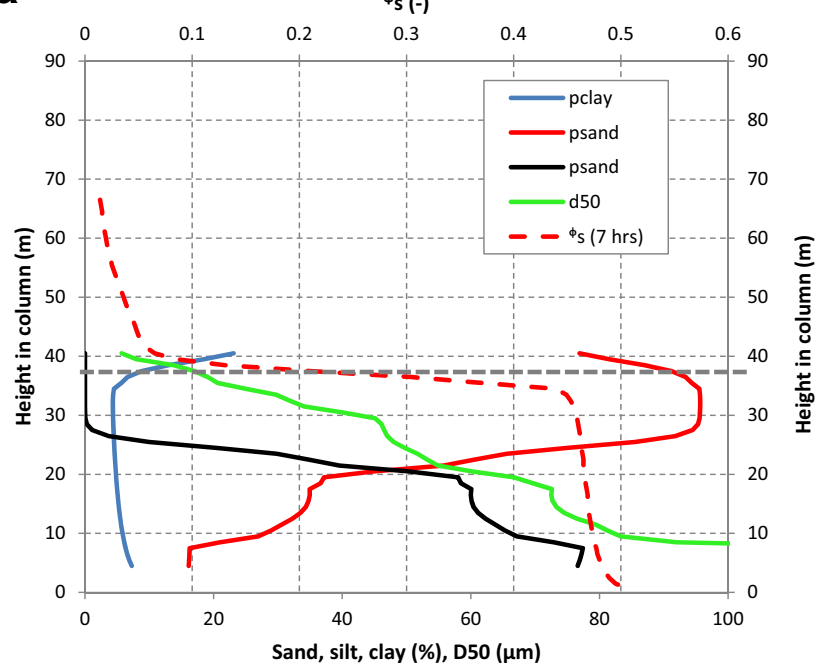

b $\phi_{\mathrm{S}}[-]$

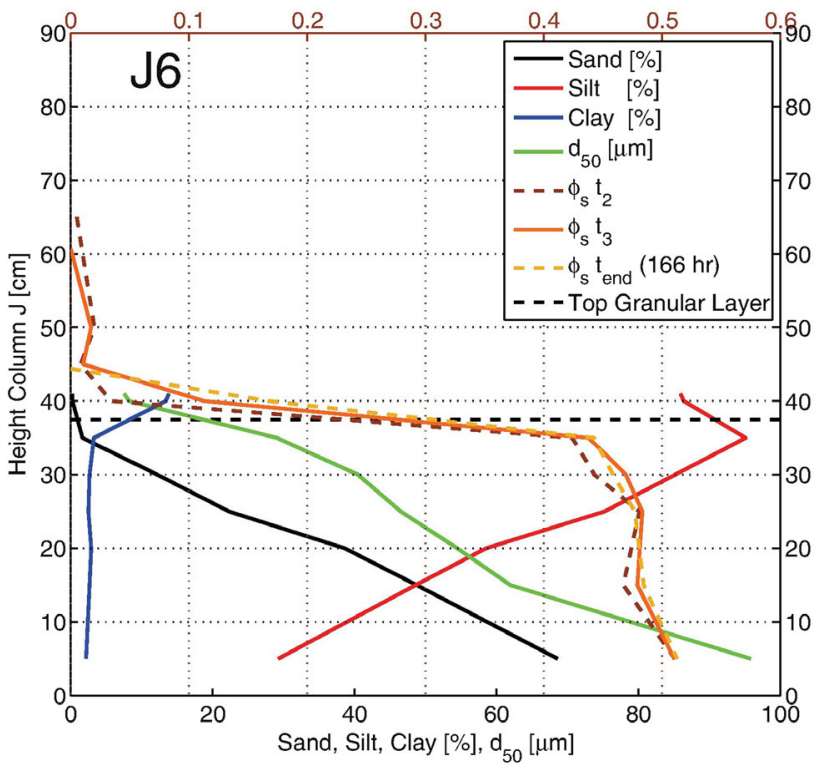

Fig. 11 Predicted (top) and measured (bottom) variation in particle size distribution and volumetric concentration, test J6. Data from Te Slaa et al. (2013). Bottom figure shown with the kind permission of Springer

sediments ranging from slightly sandy clayey silt to clayey very sandy silt.

\subsection{Van and Pham Van Bang (2013) experiments}

Van and Pham Van Bang (2013) used a form of the MLB equation to model a variety of monodisperse and polydisperse sediments using a fourth-order weighted essentially non-oscillatory (WENO) scheme developed by Dumbser et al. (2008). The form of the MLB equation they used was as follows (presented here 
for a bidisperse solution of flocculated mud, denoted by the subscript $f$, and of sand, denoted by the subscript $s$ ):

$$
\begin{aligned}
& W_{s}^{s}=(1-\phi)^{n-2}\left(1-\phi_{m}-\phi_{s}\right)\left[w_{s, 0}^{s} \frac{\mu_{0}}{\mu}\left(\frac{\rho_{\text {sand }}-\rho_{\text {suspension }}}{\rho_{\text {sand }}-\rho_{w}}\right)\left(1-\phi_{s}\right)-w_{s, 0}^{m}\left(\frac{\rho_{\text {mud }}-\rho_{\text {suspension }}}{\rho_{\text {mud }}-\rho_{w}}\right) \phi_{m}\right] \\
& W_{s}^{m}=(1-\phi)^{n-2}\left(1-\phi_{m}-\phi_{s}\right)\left[w_{s, 0}^{m}\left(\frac{\rho_{\text {sand }}-\rho_{\text {suspension }}}{\rho_{\text {sand }}-\rho_{w}}\right)\left(1-\phi_{m}\right)-w_{s, 0}^{s} \frac{\mu_{0}}{\mu}\left(\frac{\rho_{\text {sand }}-\rho_{\text {suspension }}}{\rho_{\text {sand }}-\rho_{w}}\right) \phi_{s}\right]
\end{aligned}
$$

where $\phi_{m}$ is the volume concentration of the mud sediment particles, $\rho_{\text {mud }}$ and $\rho_{\text {sand }}$ are the densities of the mud and sand particles, respectively, $\rho_{\text {mixture }}$ is the bulk density of the mud/ sand/water mixture, $\mu_{0}$ is the viscosity of the suspension fluid and $\mu$ is the viscosity of the mud-water mixture.

This equation has two modifications compared to the standard MLB formula (Eq. 28). The first is the addition of a buoyancy term $\left(1-\phi_{m}-\phi_{s}\right)$, which as we have seen is not required as the buoyancy term is already inherent in the MLB equation. The other addition was the $\mu_{0} / \mu$ viscosity term. This term was added to represent more fully the effect of suspended sediment on the viscosity of the suspension and hence on settling velocity (which is not well reproduced in the Richardson-Zaki equation for mixed mud/sand sediments). The term added by Van and Pham Van Bang (2013) contributes the change in viscosity from the mud only to the settling of sand. The mMLB method in this paper presents an alternative solution to the same issue but retaining the contribution to viscosity of the sand and colloidal fractions.

Van and Pham Van Bang (2013) obtained good results for their model predictions when compared against data. However, the results were obtained by fitting the value of the Richardson and Zaki exponent $n$ empirically with numbers as high as $n=23$. This is a drawback to the version of the MLB equation (Eq. 42) proposed by Van and Pham Van Bang. The alternative form of the MLB equation proposed in this paper is applied to the data of Van and Pham Van Bang and is successful at reducing the extent of this empiricism.

In their paper, Van and Pham Van Bang use the results of an experiment undertaken by Nguyen (2008) using kaolin and sand from Fontainebleau (France) which is a narrowly uniformly graded mixture with a d50 of $199 \mu \mathrm{m}$. The settling column used for the laboratory experiments was $1.5 \mathrm{~m}$ in height and instrumented by gamma ray probe to measure the density profiles at different times.

Firstly, the kaolin-only case is modelled to allow calibration of the cohesive sediment settling velocity $\left(w_{s, 0}^{m}\right)$ before attempting to reproduce settling of the sand-kaolin mixture. This test involved an initial concentration of $100 \mathrm{~kg} / \mathrm{m}^{3}$ ( $\phi=0.037$ ). Nguyen (2008) estimated the gelling concentration of the kaolin to be $530 \mathrm{~kg} / \mathrm{m}^{3}\left(\phi_{g e l}=0.2\right)$. This is a high value compared to the results of other researchers working with kaolin in settling columns and with reported gelling concentrations in general (e.g. Dankers 2006, $70-130 \mathrm{~kg} / \mathrm{m}^{3}, \phi_{\text {gel }}=0.026-0.049$; Whitehouse et al. 2000 and Winterwerp 2002, 80-180 kg/m $\left.\mathrm{m}^{3}, \phi_{\text {gel }}=0.03-0.07\right)$. For this reason, implementation of the mMLB model included calibration of a (lower) value of $\phi_{\text {gel }}$. Van and Pham Van Bang estimated the $w_{s, 0}$ value to be $0.164 \mathrm{~m} / \mathrm{s}$ and found the best-fit value of $n$ to be 12.5. The present model results are derived with $w_{s, 0}=0.08 \mathrm{~mm} / \mathrm{s}$ and with $\phi_{\text {gel }}=0.09$. The value of $D_{H}$ for this model application was the same as the Te Slaa application in Sect. 3.3 above.

Figure 12 shows the results of the mMLB model of the present study, together with the observations of Nguyen (2008). It can be seen that the mMLB of this paper performs reasonably well.

The observations display more dispersion around the lowering interface than the mMLB model. This is likely to be due to small variations in the settling velocity of the flocs of the

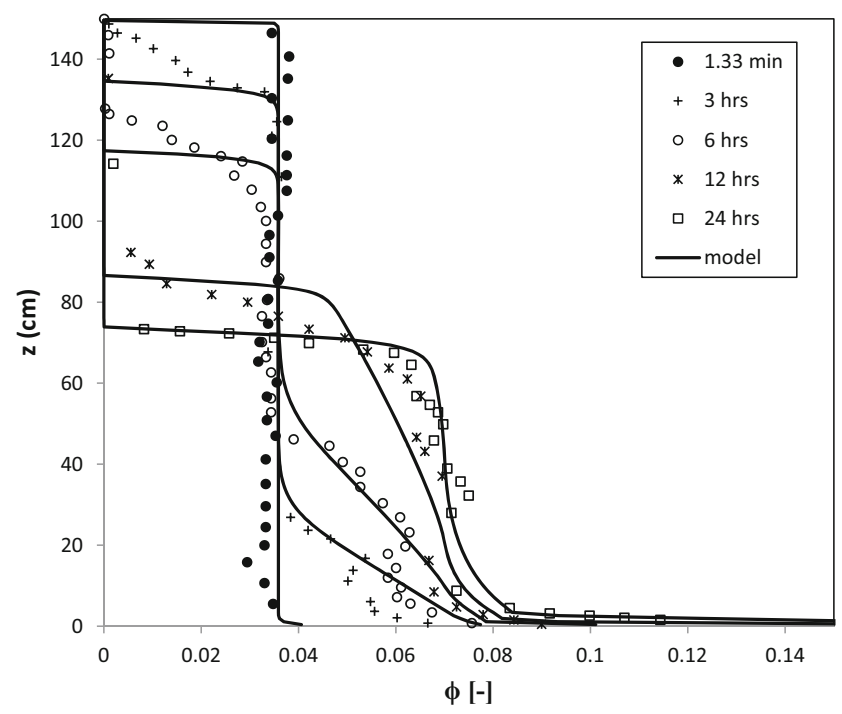

Fig. 12 Predicted and measured variation in volumetric concentration with time and height for settling of kaolin solution with initial concentration of $100 \mathrm{~kg} / \mathrm{m}^{3}$ (Van and Pham Van Bang 2013). Present study model (black lines). Measurements by Nguyen (2008) (symbols) 
settling fluid rather than any hydrodynamic diffusion (Nguyen and Ladd 2005).

The case with sand and kaolin is shown in Fig. 13. This is cited in Van and Pham Van Bang (2013) as being a solution with initial concentrations of sand $/$ mud of $20 / 80 \mathrm{~kg} / \mathrm{m}^{3}(\phi=$ 0.007/0.03) though the results in Fig. 13 indicate that the initial concentrations are more like $25 / 75 \mathrm{~kg} / \mathrm{m}^{3}$ which were the values used for the mMLB prediction here. Van and Pham Van Bang (2013) achieve a good fit to the observed behaviour through setting the Richardson-Zaki exponent $n$ to the high value of 23. The mMLB model used a (calibrated) value of $\phi_{g e l}=0.10$, which is very slightly higher than for the kaolinonly experiment, together with a value of $\phi_{\max }=0.37$. In order to ensure that any effects of polydispersivity of the sand fraction were captured, the mMLB model was run with seven fractions (of which six were sand-75, 100, 150, 200, 250 and $300 \mu \mathrm{m}$ - and the other the cohesive clay fraction).

In general, the mMLB is good at capturing the settling behaviour of the mud fraction, but the model is less good at reproducing the relatively steep gradation sediment near the sand-kaolin interface where the concentration gradients are highest. This gradation would be improved through a higher order solver (as for instance used in Van and Pham Van Bang 2013) though this subject is outside of the focus of this paper. In addition, in contrast to the kaolin-only result, there is noticeable broadening of the front of clay suspension/water interface in the measured data. The reason for this is not clear. It is noted that this broadening of the settling front is captured by the Van and Pham Van Bang (2013) model, but the authors do not discuss this feature.

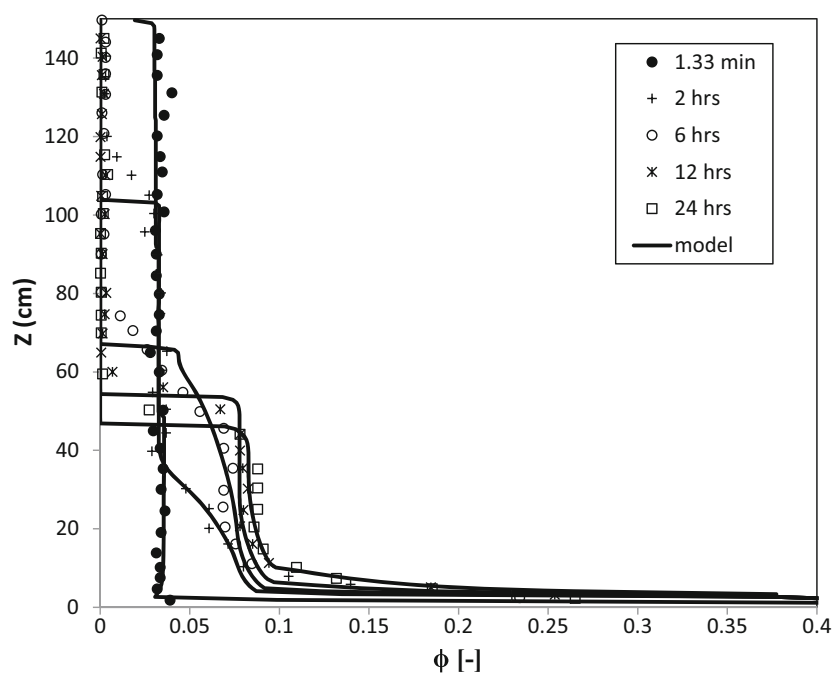

Fig. 13 Predicted and measured variation in volumetric concentration with time and height for settling of mixed kaolin/sand solution with initial concentration of 75/25 kg/m $\mathrm{m}^{3}$ (Van and Pham Van Bang 2013). Present study model (black lines). Measurements by Nguyen (2008) (symbols)

\section{Discussion and conclusions}

The hindered settling of monodisperse particles has been well discussed in the literature, but the various approaches applied to describing hindered settling tend to underestimate the hindered settling effect as the sediment concentration approaches the gelling concentration (cohesive) or maximum packing concentration (non-cohesive). A modified form of the Richardson and Zaki (1954) formula is proposed which significantly improves the original form of the Richardson and Zaki equation and which also incorporates the permeability of suspensions as they approach the maximum packing/gelling point.

For polydisperse non-cohesive suspensions, the Richardson and Zaki formula has been generalised and the MLB formula developed by Masliyah (1979) and Lockett and Bassoon (1979) is commonly recognised as being the most successful of these polydisperse formulae. For mixed suspensions of cohesive and non-cohesive material, the evidence of researchers (e.g. Van and Pham Van Bang 2013) is that the hindering effect in settling mixed and cohesive suspensions can be much more than implied by the RichardsonZaki and MLB formulae. It is postulated in this paper that a modified form of the MLB formula, taking into account the modifications to monodisperse hindered settling discussed in the paragraph above, improves the usefulness and performance of the MLB formula for non-cohesive, cohesive and mixed suspensions.

The mMLB method presented in this paper has been shown to reproduce the observed hindered settling for kaolin, for polydisperse non-cohesive sediments and for a range of mixtures of sand and mud. The success of the method is utilised without recourse to empirical fitting the value of $n$. On this basis, the mMLB method is proposed as an improvement to the method of Masliyah (1979) and Lockett and Bassoon (1979) for mixed sediments. The exponents $n^{\prime}$ (which incorporates the effective sediment volume concentration, $\phi / \phi_{\max }$, in the viscosity term) and $m$ (which incorporates the effective sediment volume in the return current term) as used in this study are together subtly different to the exponent of $n$ used by Richardson and Zaki for hard spheres (which uses standard sediment volume concentration, $\phi$, in the viscosity term). This difference can be physically justified on the basis of settling velocity experiments (e.g. Baldock et al. 2004) and of experiments of the effect of changing sediment concentration on the viscosity of sediment suspensions (e.g. Quemada 1977).

Comparison of the predictions of the mMLB model with experimental data showed that, in general, the observed densities of deposited beds could only be correctly predicted through the empirical setting of sediment packing parameters and/or gelling concentrations of the flocculating fractions. Whilst the new method has not removed all of the empiricism 
and uncertainty considered with predicting hindered settling, the new model moves the focus of attention from empirical assessment of the Richardson-Zaki exponent $n$, which cannot be satisfactorily defined in terms of rheological and structural properties of polydisperse fractions, to the rheological and structural properties themselves, and particularly the effective volume concentrations of floc-grain mixtures. This can only lead to improvement in the representation of polydisperse settling as the understanding of the packing of mixed sediments improves.

The first-order scheme used in this paper to illustrate the mMLB model was found to give reasonable results for polydisperse hindered settling of mud and sand-but the firstorder model struggled to predict the gradation of the claysilt-sand deposit accurately owing to the high concentration gradients near the sand interface. For coastal modelling, it is considered that a practical but higher order scheme is required rather than the one used in this report. Nevertheless, the model used in the study was sufficiently accurate to exhibit the strength of the proposed mMLB method.

$A$, cross-sectional area of sediment particle; $c_{i}^{k}$, masssuspended sediment concentration of the $k$ th sediment fraction at the $i$ th vertical layer of the model; $C_{D}$, the (dimensionless) drag coefficient which depends on the shape of the object and on the Reynolds number; $d$, diameter of sediment particle; $d_{i}$, the $i$ th sediment fraction; $D_{*}=\left[\frac{g(s-1)}{\nu^{2}}\right]^{1 / 3}$, dimensionless particle size; $D$, diameter of the container vessel; $D_{f}$, fractal dimension of flocs; $D_{H}$, diffusion caused by the randomly fluctuating motion; $D_{s}$, molecular diffusion coefficient; $F_{D}$, drag force; $\boldsymbol{F}$, tridiagonal matrix with component, $F_{i, j} ; \boldsymbol{G}$, single column matrix with component $G_{i} ; g$, gravitational acceleration; $i$, hydraulic conductivity; $k$, permeability given by the Kozeny-Carman equation; $K_{k}$, empirical parameter; $n, n^{\prime},, m$, exponents in the Richardson-Zaki and modified Richardson-Zaki equations; $\Delta n^{\prime \prime}$, correction required for the Richardson-Zaki equation exponent $n^{\prime}$ to reflect the linear fit used by Richardson and Zaki; $R e_{p}$, Reynolds particle number; $s$, specific gravity; $S_{i i}, S_{i j}$, empirical parameters used in the Davis and Gecol (1994) settling formula; $S_{i}^{j}$, sediment flux for the $j$ th fraction at the $i$ th model layer; $w_{f}$, settling velocity associated with the point of fluidisation of the bed; $w_{s}$, slip velocity of sediment including hindering effect before the effects of multiple sediment fractions are included; $w_{s, i}^{k}$ as $w_{s}$, but referring to the $k$ th sediment fraction at the $i$ th vertical layer; $W_{s}$, slip velocity of sediment including the polydisperse hindering effect; $W_{s, i}^{k}$, slip velocity (including polydisperse hindered settling) of the $k$ th sediment fraction at the $i$ th vertical layer; $w 1_{s, i}^{k}, w 2_{s, i}^{k}$ as $w_{s, i}^{k}$, but specifically for hindered settling (1) and fluidisation (permeability) (2), respectively; $w_{s, 0}, w_{s, 0}^{s}, w_{s, 0}^{m}$, terminal particle settling velocity of a single particle in an still water, the $s$ and $m$ superscripts refer to sand and mud particles; $\Gamma_{T}$, eddy diffusivity; $\Gamma_{c}$, consolidation diffusion coefficient; $\varepsilon$, porosity; $\lambda_{i j}=d_{j} / d_{i} ; \phi_{s}$, volume concentration of sand particles; $\phi_{m}$, volume concentration of mud particles; $\phi_{\text {clay }}$, volume concentration of clay particles; $\phi_{p}, \phi$, volume concentration of sediment; $\phi_{\max }$, maximum packing volume; $\phi_{\text {gel }}$, volume concentration at which gelling occurs; $\phi_{f l o c}, \phi_{f l o c, \text { max }}$, floc volume concentration and the maximum volume concentration of flocs; $\mu, \nu$, dynamic and kinematic viscosities of the fluid; $\rho_{s}, \rho_{\text {mud }}, \rho_{\text {sand }}$, density of sediment, sand particles and mud particles, respectively; $\rho_{i}$, density of the $i$ th sediment fraction; $\rho_{w}$, density of the fluid; $\rho_{\text {suspension }}$, density of the sediment suspension.

Acknowledgements Professor Manning's contribution to this manuscript was partly funded by HR Wallingford Company Research project 'FineScale - Dynamics of Fine-grained Cohesive Sediments at Varying Spatial and Temporal Scales' (DDY0523).

\section{References}

Al-Naafa MA, Selim MS (1989) Sedimentation of polydisperse concentrated suspensions. Can J Chem Eng 67:253-264

Amy, L.A., Talling, P.J., Edmonds, V.O., Sumner, E.J. and Lesueur, A. (2006). An experimental investigation of sand-mud suspension settling behaviour: implications for bimodal mud contents of submarine flow deposits

Baldock T, Tomkins MR, Nielsen P, Hughes MG (2004) Settling velocity of sediments at high concentrations. Coast Eng 51:91-100

Batchelor GK (1982) Sedimentation in a batch of dilute polydisperse system of interacting spheres, Part 1: General Theory. Journal of Fluid Mechanics 119:379-408

Batchelor GK, Wen CS (1982) Sedimentation in a dilute polydisperse system of interacting spheres:Part 2. Numerical results, Journal Fluid Mechanics 124:495-528

Baugh JV, Manning AJ (2007) An assessment of a new settling velocity parameterisation for cohesive sediment transport modelling. Cont Shelf Res. doi:10.1016/j.csr.2007.03.003

Bergougnoux L, Ghicini S, Guazzelli E, Hinch J (2002) Spreading fronts and fluctuations in sedimentation. Physical Fluids 15:1875-1887

Berres S, Burger E, Tory EM (2005) Applications of polydisperse sedimentation models. Chem Eng J 111:105-117

Bürger R, García A, Karlsen KH, Towers JD (2008) A family of numerical schemes for kinematic flows with discontinuous flows. Journal of Engineering Mathematics 60(3):387-425

Burger R, Karlsen KH, Tory EM, Wendland WL (2002) Model equations and instability regions for the sedimentation of polydisperse suspensions of spheres. ZAMM Z Angew Math Mech 82(10):699-722

Camenen B (2008) Settling velocity of sediments at high concentration. In: Kusada T, Yamanishi H, Spearman J, Gailani J (eds) Sediment and Ecohydraulics, INTERCOH 2005. Elsevier, Amsterdam, pp 211-226

Camenen B, Pham Van Bang D (2011) Modelling the settling of suspended sediments for concentrations close to the gelling concentration. Cont Shelf Res 31:106-111

Chesher TJ, Ockenden MC (1997) Numerical modelling of mud and sand mixtures. In: Burt N, Parker R, Watts J (eds) Cohesive Sediments Proc. of INTERCOH Conf. Wiley, (Wallingford, England), Chichester, pp 395-406

Chong JS, Christiansen EB, Baer AD (1971) Rheology of concentrated suspensions. J Appl Polym Sci 15:2007-2021 
Coulson JM, Richardson JF (1955) Chemical engineering, vol 2. Pergamon press, London

Cuthbertson A, Dong P, King S, Davies P (2008) Hindered settling velocity of cohesive/noncohesive sediment mixtures. Coastal Engineering 55(12):1197-1208

Dankers PJT (2006) On the hindered settlling of suspensions of mud and mud-sand mixtures. Doctoral Thesis for the Technical University of Delft, Netherlands

Davies R (1968) The experimental study of the differential settling of particles in suspension at high concentrations, Proceedings of the International Conference on Powder Technology, Chicago, May 2023, 1968, Powder technology. Elsivier, Netherlands

Davis RH, Gecol H (1994) Hindered settling function with no empirical parameters for polydisperse suspensions. AIChE Journal 40(3):570 575

Davies R, Kaye BH (1971) Experimental investigation into the settling behaviour of suspensions, Proceedings of PowTech, 71: International Powder Technology and Bulk Grabular Solids Conference, 1971

Dorrell R, Hogg AJ (2010) Sedimentation of bidisperse dispersion. Int J Multiphase Flow 36:481-490

Dorrell RM, Hogg AJ, Sumner EJ, Talling PJ (2011) The structure of the deposit produced by sedimentation of polydisperse suspensions. J Geophys Res Earth Surf 116(1):F01024

Dumbser M, Enaux C, Toro EF (2008) Finite volume schemes of very high order of accuracy for stiff hyperbolic balance laws. J Comp Phys 227:3971-4001

Faas RW (1984) Time and density-dependent properties of fluid mud suspensions in NE Brazilian Continental Shelf. Geo-Mar Lett 4: $147-152$

Garside J, Al-Dibouni MR (1977) Velocity-voidage relationship for fluidization and sedimentation in solid-liquid systems. Ind. Eng. Chem., process Des Dev 16:206-214

Gratiot N, Manning AJ (2007) A laboratory study of dilute suspension mud floc characteristics in an oscillatory diffusive turbulent flow. J Coast Res SI 50:1142-1146

Ha Z, Liu S (2002) Settling Velocities of Polydisperse Concentrated Suspensions. The Canadian Journal of Chemical Engineering 80(5):783-790

Harper MA, Harper JF (1967) Measurements of diatom adhesion and their relationship with movement. Br Phycological Bull 3:195-207

Koch DL, Shaqfeh ESG (1991) Screening in sedimenting suspensions. J Fluid Mech 224:275-230

Kothari AC (1981) Sedimentation of Multisized Particles, MS Thesis. Texas Technology University, Lubbock

Kranck K (1984) The role of flocculation in the filtering of particulate matter in estuaries. In: Kennedy V (ed) The Estuary as a Filter. Academic Press, Orlando Inc, pp 159-175

Kranenburg C (1992) Hindered settlign and consolidation of mud - analytical results, Report number 11-92. Delft University of Technology, Netherlands

Krieger IM, Dougherty TJ (1959) A mechanism for non-Newtonian flow in suspension of rigid spheres. Trans Soc Rheol 3:137-152

Krone RB (1963) A study of rheological properties of estuarial sediments. Report No. 63-68, Hyd. Eng. Lab. and Sanitary Eng. Lab. University of California, Berkeley, pp 63-68

Leng, D.E., Katti, S.S. and Atiemo-Obeng V. (2009). Industrial mixing technology, In: L.F. Albright (ed), Albrights Chemical Engineering Handbook, CRC Press, Boca Raton, pp615-707.

Little C (2000) The biology of soft shores and estuaries. Oxford University Press, UK 252p

Liu S (2000) Suspension flow in pipeline. Recent Res. Devel. Chemical Engg. 4:161-233

Lockett MJ, Al-Habbooby HM (1974) Relative particle velocities in twospecies settling. Powder technology 10:67-71
Lockett MJ, Bassoon KS (1979) Sedimentation of binary particle maixtures. Powder Technology 24:1-7

Manning AJ, Baugh JV, Spearman J, Whitehouse RJS (2010) Flocculation settling characteristics of mud:sand mixtures. Ocean Dyn 60:237-253. doi:10.1007/s10236-009-0251-0

Manning AJ, Baugh JV, Soulsby RL, Spearman JR, Whitehouse RJS (2011a) Cohesive sediment flocculation and the application to settling flux modelling. In: SS Ginsberg (ed) 'Sediment Transport', Publisher: InTech (Vienna), Chapter 5, pp. 91-116. doi:10.5772 $/ 16055$

Manning AJ, Baugh JV, Spearman J, Pidduck EL, Whitehouse RJS (2011b) The settling dynamics of flocculating mud-sand mixtures: part 1 - empirical algorithm development. Ocean Dyn 61(2-3):311350. doi:10.1007/s10236-011-0394-7

Manning AJ, Whitehouse RJS, Soulsby RL (2012) Methods for predicting suspensions of mud. Technical Report, HR Wallingford Ltd http://eprints.hrwallingford.co.uk/661/1/TR104.pdf

Masliyah JH (1979) Hindered settling in a multi-species particle system. Chem Eng Sci 34(1979):1166-1168

Maude AD and Whitmore RL (1958) A generalized theory of sedimentation. Brit J Appl Phys 9:477-482

Mehta, A.J., Jaeger, J.M., Valle-Levinson, A., Hayter, E.J., Wolanski, E. and Manning, A.J. (2009). Resuspension Dynamics in Lake Apopka, Florida. Final Synopsis Report, submitted to St. Johns River Water Management District, Palatka, Florida, June 2009, Report No. UFL/COEL-2009/00, 158p

Merckelbach LM and Kranenburg C (2004) New constitutive equations for soft mud-sand mixtures. Géotechnique 54(4):235-243

Merckelbach L (2000) Consolidation and strength evolution of soft mud layers, Communications on Hydraulic and Geotechnical Engineering, PhD thesis for Delft University of Technology. Geotechnical Engineering, report 00-2, Delft University of Technology

Mirza S, Richardson JF (1979) Sedimentation of suspensions of particles of two or more sizes. Chemical Engineering Science 34(4):447-454

Mucha PJ, Brenner MP (2003) Diffusivities and front propagation in sedimentation. Phys Fluids 15(5):1305-1313

Nguyen QD (2008) Etude expérimentale et numérique du début de consolidation de sols de très forte teneur en eau. PhD. thesis. Université de Nantes, France In French

Nguyen NQ, Ladd AJC (2005) Sedimentation of hard-sphere suspensions at low Reynolds number. J Fluid Mech 525:73-104

Paterson, D.M. and Hagerthey, S.E. (2001). Microphytobenthos in contrasting coastal ecosystems: Biology and dynamics. In: Ecological comparisons of sedimentary shores (K. Reise, Ed.), Ecological studies, pp. 105-125

Quemada D (1977) Rheology of concentrated disperse systems and minimum energy dissipation principle. Rheol Acta 16:82-94

Richardson JF, Zaki WN (1954) Sedimentation and fluidization: part I. Trans Instn Chem Engrs 32:35-53

Ross MA (1988) Vertical structure of estuarine fine sediment suspensions. Ph.D. thesis. University of Florida, Gainesville

Rowe PN (1987) A convenient empirical equation for estimation of the Richardson-Zaki exponent. Chem.Eng.Sci. 43:2795-2796

Schiller, L. and Naumann, A. (1933). Uber die grundlegenden Berechnungen bei der Schwerkrauftbereitung, Z.,VDI, volume 77. (In German)

Siwiec T (2007) The experimental verification of Richardson-Zaki law on example of selected beds used in water treatment. J Polish Agric Univ 10(2):5

Smith SJ, Freidrichs CT (2011) Size and settling velocities of cohesive flocs and suspended sediment aggregates in a trailing suction hopper dredge plume. Cont Shelf Res 31:S50-S63

Soulsby RL (1997) Dynamics of marine sands. Thomas Telford Publications, London 
Soulsby RL, Manning AJ, Spearman J, Whitehouse RJS (2013) Settling velocity and mass settling flux of flocculated estuarine sediments. Mar Geol. doi:10.1016/j.margeo.2013.04.006

Spearman J, Manning AJ, Whitehouse RJS (2011) The settling dynamics of flocculating mud-sand mixtures: part 2-numerical modelling. Ocean Dyn 60(2):237-253

Te Slaa S, He Q, van Maren DS, Winterwerp JC (2013) Sediment processes in silt rich sediment systems. Ocean Dyn 63:399-421

Tolhurst TJ, Gust G, Paterson DM (2002) The influence on an extracellular polymeric substance (EPS) on cohesive sediment stability. In: Winterwerp JC, Kranenburg C (eds) Fine sediment dynamics in the marine environment - proceedings in marine science 5. Elsevier, Amsterdam, pp 409-425

Toorman E (1996) Sedimentation and self-weight consolidation: general unifying theory. Géotechnique 46(1):103-113

Toorman E (1997) Modelling the thixotropic behaviour of dense cohesive sediment suspensions. Rheol Acta 36:56-65

Toorman EA (1999) Sedimentation and self-weight consolidation: constitutive equations and numerical modelling. Geotechnique 49(6): 709-726

Van LA, Pham Van Bang D (2013) Hindered settling of sand/mud flocs mixtures: from model formulation to numerical validation. Adv Water Resour 53:1-11

van Ledden M (2002) A process-based sand-mud model. In: Winterwerp JC, Kranenburg C (eds) Fine Sediment Dynamics in the Marine Environment - Proc. in Mar. Science 5. Elsevier, Amsterdam, pp $577-594$

van Olphen H (1977) An introduction to clay colloid chemistry, 2nd edn. Wiley, London $318 \mathrm{p}$

Van Rijn LC (1993) Principles of sediment transport in rivers, estuaries and coastal seas. Aqua Publications, Amsterdam

van Rijn LC (2007) Unified view of sediment transport by currents and waves. II: Suspended Transport, Journal of Hydraulic Engineering 133(6):668-689
Waeles B, Le Hir P, Lesueur P (2008) A 3D morphodynamic processbased modelling of a mixed sand/mud coastal environment : the seine estuary, France. In: Kudusa T, Yamanishi H, Spearman J, Galiani JZ (eds) Sediment and Ecohydraulics - Proc. in Marine Science 9. Elsevier, Amsterdam, pp 477-498

HR Wallingford (1990) Fluid mud in estuaries, Field measurements, HR Wallingford Report EX2076, January 1990

Wang, Z.Y., Larsen, P. and Xiang, W. (1994). Rheological properties of sediment suspensions and their implications, Journal of Hydraulic Research, IAHR,495-516

Wang Z, Nestmann F, Dittrich A (1995) Fall velocity of sediment in clay suspensions, Procedings of the Sixth International Syposium on River sedimentation. Central Board of Irrigation and Power, New Delhi published by A.A. Balkema

Whitehouse RJS, Soulsby RL, Roberts W, Mitchener HJ (2000) Dynamics of estuarine muds. Thomas Telford, London, $210 \mathrm{pp}$

Winterwerp JC (1999) On the dynamics of high-concentrated mud suspensions. Ph.D. Thesis. Delft University of Technology, Faculty of Civil Engineering and Geosciences, The Netherlands $172 \mathrm{p}$

Winterwerp JC (2002) On the flocculation and settling velocity of estuarine mud. Cont Shelf Res 22(9):1339-1360

Winterwerp JC, Van Kesteren WGM (2004) Introduction to the physics of cohesive sediment dynamics in the marine environment. In: van Loon T (ed) Developments in sedimentology, 56. Elsevier, Amsterdam, 466p

Winterwerp JC, Manning AJ, Martens C, de Mulder T, Vanlede J (2006) A heuristic formula for turbulence-induced flocculation of cohesive sediment. Estuar Coast Shelf Sci 68:195-207

Wu W, Wang SY (2006) Formulas for sediment porosity and settling velocity. J Hydrual Eng 132(8):858-862

Yin X, Koch DL (2008) Velocity fluctuations and hydrodynamic diffusion in finite-Reynolds-number sedimenting suspensions. Phys Fluids 20:043305 